\title{
Time Inconsistent Preferences and the Annuitization Decision
}

\author{
Philipp Schreiber* $\quad$ Martin Weber ${ }^{\dagger}$
}

June 2013

\begin{abstract}
Good news can involve difficult decisions. For example winning a lottery jackpot can go along with the decision, whether to have the jackpot paid out immediately as a lump sum or as periodic annual payments. Also when entering retirement most people face the decision whether they want their defined contribution account balance paid as a lump sum or to annuitize that amount. The fact that people tend to choose the lump sum even if economic reasons suggest that they should choose the annuity is called the annuity paradox. In a large online survey we find that people behave time inconsistent: older people have a stronger tendency to choose the lump sum than younger people when they are asked to predict today what to choose when they retire. This effect is considerably stronger for participants that answer simple time preference questions inconsistently. Our findings suggest to think about precommitment devices for the annuitization decision.
\end{abstract}

* University of Mannheim, Department of Banking and Finance, Email: schreiber@ bank.bwl.uni-mannheim.de

$\dagger$ University of Mannheim, Department of Banking and Finance, Email: weber@bank.bwl.uni-mannheim.de

We would like to thank the Frankfurter Allgemein Zeitung for conducting the study with us. Intensive discussion with two journalists, Anne-Christin Sievers and Patrick Bernau, helped to considerably improve the questionnaire. We also would like to thank seminar participants at the University of Mannheim, Zeppelin University Friedrichshafen, University of California, Los Angeles, Yale University, Connecticut and Columbia University, New York and participants of the Boulder Summer Conference on Consumer Financial Decision Making, SAVE-PHF Conference on "Demographic Trends, Savings and Retirement Security: Stylized Facts and Behavioral Responses", the Falling Walls Lab 2012, the International Meeting of Experimental and Behavioral Economics 2013 and the HeiMax Workshop participants for their valuable suggestions. 


\section{Introduction}

Winning the state lottery of California is a beautiful thing but it is accompanied by a tough decision: The SuperLOTTO Plus jackpot can either be paid out in 26 annual installments or as one big lump sum payment ${ }^{1}$. Unfortunately, most of us won't have to deal with this kind of decision problem as a consequence of winning the jackpot of some national lottery. However, at time of retirement people are increasingly faced with the decision to take out a lump sum of money from their retirement account or to opt for an annuity payment (for example in 401(k) plans). Based on standard theoretical analysis, people should opt for the annuity payment to maximize expected utility. However, empirically people by a vast majority opt for the lump sum, both in the retirement and lottery case. This behavior is called the "annuity puzzle". Since Yaari (1965) there has been plenty of research focusing on how to model the observed behavior in the retirement case, i.e. explain the annuity puzzle. But even the intake of a bequest motive, background risk, incomplete markets, adverse selection and many other factors only partly explains the low demand for annuities. One aspect which all these models have in common is that they assume rational behavior of modeled agents. Brown (2007) states that "[. . . ] the mixed success of explaining annuitization behavior in a fully rational context suggests that other factors are at play." These others factors can be found in the behavioral economics literature of retirement saving and planning. The recent literature on the annuity puzzle incorporates factors such as framing, loss aversion, endowment effects and others to explain real life decisions.

In this paper, we focus on peoples' time preference and its importance in a choice between a monthly payment and a lump sum payment. It is well known that decision makers time preferences can best be described by hyperbolic discounting (see for example Ainslie and Herrnstein, 1981; Thaler, 1981; Benzion et al., 1989; Ahlbrecht and Weber, 1997). Hyperbolic discounting leads to strong discounting for outcomes in the near future and subsequently weaker discounting for distant ones which might lead to time inconsistent behavior.

To our knowledge, we are the first to relate time preferences to the annuitization decision. We investigate which annuitization decisions are implied by hyperbolic discounting and test this implication using a questionnaire study. We conduct a large online survey in cooperation with one of the biggest German newspapers, "Frankfurter Allgemeine Zeitung" (FAZ). Throughout the whole study subjects had to choose between a lump sum payment and a fair annuity. We used two frameworks: In what we call the immediate case, subjects are asked to choose between a lump sum paid out today and a (fair) annuity also starting today (comparable to the decision problem when winning the California lottery). In the deferred case, participants choose between an annuity starting at retirement age and a lump sum also received when entering retirement. Each subject was asked to choose between the annuity and the lump sum followed by a consecutive question

1 The jackpot payment options can be found on the official California Lottery website. 
to choose an annuitization rate between $0 \%$ and $100 \%$ in steps of $10 \%$. Note that, by definition, the expected value of the lump sum is equal to the expected value of the fair annuity. Taking hyperbolic discounting into account, simple calculations show that older people will prefer the lump sum over the annuity. The effect reverses for younger people where hyperbolic discounting leads to a preference for annuity payments. This is true for the immediate and the deferred decision.

The data shows that in both cases young people have a strong preference for annuities whereas older people tend to prefer lump sum payments. We find an increase of about $20 \%$ in annuitization from the oldest $10 \%$ to the youngest $10 \%$. Also, the annuitization rate increases by about $12 \%$ from the oldest to the youngest decile. This finding is in line with Brown et al. (2012) who find a negative effect of age on the annuitization decision using Croatian pension data. The age effect gets stronger for participants whose answers to simple time preference questions indicate that they follow stronger hyperbolic discounting. Further results show that risk preferences, subjective life expectancy and financial literacy are important factors to understand the annuitization decision. The more risk averse participants are, the less likely they are to choose the lump sum leading to a corresponding increase in the annuitization rate. Comparing the most risk averse to the least risk averse participants results in a difference of about $15 \%$ points in probability of choosing the annuity. The effect of subjective life expectancy is even stronger. Although most participants overestimate their life expectancy, we find that the longer someone expects to live the more likely he/she is to annuitize. Finally, controlling for financial literacy, we find that more financial literate people tend to prefer the annuity.

The findings are particular important as people face the annuitization decision late in life and therefore, following hyperbolic discounting, are more likely to choose a lump sum. In the deferred case, the switch of preferences can be seen as a self-control problem of participants as they make the optimal decision (according to expected utility theory) when thinking about what to choose in the future but they reverse the decision once the day of the actual decision has arrived. These results imply that there are two ways to increase annuitization. 1) By introducing a commitment device allowing people to bind or precommit their behavior (see Strotz, 1955). If people choose the lump sum because of self-control problems a precommitment device is a powerful tool to help people overcome this problem (see for example Thaler and Shefrin, 1981; Laibson, 1997; Beshears et al., 2011). 2) Making it mandatory to determine the payout scheme at the beginning of the contract when people are (still) young and not at retirement, is another way to increase real life annuitization rates. Reversing this decision has to be associated with a cost (either monetary or effort-wise, e.g. paperwork).

\section{Overview of related literature}

Yaari (1965) was the first to extend the standard life-cycle hypothesis and include mortality risk. He showed that in a model of rational decision making, a risk averse individual with no bequest motive should annuitize 
$100 \%$ of his wealth to maximize utility. This result was confirmed forty years later by Davidoff et al. (2005) in a model with less restrictive assumptions. In contrast to these results the empirically observed annuitization rates are very low ${ }^{2}$. As a consequence, a large body of work concentrates on explaining these low rates of annuitization. In the following it is distinguished between the "rational" and "behavioral" reasons against full annuitization:

\section{Rational aspects}

\section{a) Bequest motive}

If an individual wants to leave a bequest it is not optimal for him/her to fully annuitize because annuity payments immediately stop after death. Friedman and Warshawsky (1990) study a model of saving and annuity demand and find that a bequest motive in combination with actuarial unfairly priced annuities can reduce annuity demand. Ameriks et al. (2011) also conclude that the bequest motive is an important factor to determine the individual annuity demand. In contrast, Hurd (1989) finds that the utility of a bequest is small and therefore desired bequests are small on average. He also finds that elderly households with children do not dissave more rapidly than those without children and concludes that both households have the same (small) interest in leaving a bequest. Brown (2001) examines a life-cycle model of consumption and finds that neither the presence of children nor the self reported bequest motive has any influence on the annuity demand.

\section{b) Family compensation}

Kotlikoff and Spivak (1981) compare family insurance with perfect market insurance and find that family insurance can substitute a considerable proportion of the market insurance. Brown and Poterba (2000) find that the utility gain from annuitization is smaller for couples than it is for single individuals. Also, Brown (2001) finds that marital status is an important source of variation in the annuity decision, with married couples being less likely to annuitize.

\section{c) Background risk}

Horneff et al. (2009) build a framework where the investor faces uninsurable shocks to housing, medical expenses, health, and income during the work life and retirement. They find that these uninsurable shocks increase the preference for liquid savings (e.g., bonds) only marginal. Also, Pang and Warshawsky (2010) find that health shock risk leads to precautionary savings and a shift from risky equities to riskless bonds. But with increasing age, annuities become superior to equity and bonds even in the presence of health shock risk.

\footnotetext{
$2 \overline{\text { See for example Health and Retirement Study (HRS) }} 1998$ - 2008, Buetler and Teppa (2007) or for a summary Johnson et al. (2004).
} 


\section{d) Adverse selection and unfair prices}

Finkelstein and Poterba (2004) use a data set of annuitants of a large UK insurance company. They find evidence of adverse selection in both mortality rates and policy pricing. Brunner and Pech (2006) confirm this result in a theoretical framework. Mitchell et al. (1999) value single and joint life annuities available in the market and find that annuity payments vary by $20 \%$ from the 10 highest to the 10 lowest paying companies. Murthi et al. (2000) find that the cost of annuitizing a pension upon retirement is 10-12\% of the account balance. The costs due to adverse selection account for almost two thirds of these costs.

\section{e) Further rational aspects}

Other possible explanations are incomplete annuity markets (Davidoff et al., 2005) and the crowding out of private annuitization by the government (Mitchell and Moore, 1998; Dushi and Webb, 2004; Purcal and Piggott, 2008). Despite all the efforts to explain the annuity puzzle, the success of the studies and models described above is only moderate. Even models that incorporate most of the previously mentioned factors can explain only parts of the low demand for annuities. Therefore, it seems logical to search for additional factors that may help to understand the puzzle.

\section{Behavioral aspects}

$\mathrm{Hu}$ and Scott (2007) calculate reservation prices for annuities under the standard expected utility model (EUT) and under cumulative prospect theory (CPT). Results show that under expected utility reservation prices are always above one, indicating that the annuity is attractive for the EUT-decision maker. Under CPT, almost all values are below one and therefore the annuity seems unattractive to the CPT-decision maker.

Brown et al. (2008) examine framing as a possible explanation for low annuity demand. They argue that under a consumption frame an annuity should be attractive because it serves as a form of insurance. But under a narrow investment frame the annuity can appear riskier than a bond for example, because it's payments depend on a random variable (i.e. time of death). Results of their survey study show, that if people were presented an annuity in a consumption frame, the majority chooses the annuity (72\%). In contrast, when people were faced with the same decision problem in an investment frame, only $21 \%$ preferred the annuity. Agnew et al. (2008) also find strong effects of framing on the annuitization decision.

Benartzi et al. (2011) examine the fixed, immediate payout annuity market and propose various behavioral aspects (for example loss aversion and framing) as an explanation for the low annuity demand. Brown et al. (2012) focus on the complexity of annuity products and people's ability to capture the importance of the decision. Beyond those aspects, Previtero (2012) finds a strong negative correlation between recent stock market returns and annuity sales. He argues that myopic extrapolation of stock market returns has a 
strong impact on the annuitization decision. This result is supported by Chalmers and Reuter (2012) who find a positive connection between recent stock returns and the selection of the lump sum.

Shu et al. (2013) model and measure individual preferences for annuities using a conjoint survey. This technique allows them to separately elicit preferences for different attributes of the annuity (e.g., period certain, inflation adjustment). They find that some attributes (e.g. a period-certain guarantee) are particular important as they seem to affect decision makers utility beyond their influence on the actuarial present value of the annuity.

\section{Hyperbolic discounting and measuring time preferences}

\section{Hyperbolic discounting}

Most of the theoretical work dealing with the annuity puzzle assumes rational behavior and all of it assumes that investors have stationary time preferences. According to Koopmans (1960), the only discount function that fulfills these assumptions is the exponential discount function given by $\delta(t)=\delta^{t}$ with $\delta \in(0,1]$. The stationarity of the exponential discount function leads to the constant discount rate $\delta=\frac{\delta^{t}}{\delta^{t-1}}$ between two consecutive periods. In the 1980s scientists started eliciting discount rates from decision tasks with different subjects $^{3}$. Many studies find anomalies in behavior compared to what a stationary discount function would predict (e.g., Thaler, 1981; Benzion et al., 1989; Ahlbrecht and Weber, 1997). One of the most robust findings is that individual's exhibit impatience in their decisions. This leads to strong discount rates for outcomes that are in the near future and weak discount rates for more distant ones. Thaler (1981) describes this behavior with the following example:

(A) Choose between: (A1): One apple today and (A2): Two apples tomorrow.

(B) Choose between: (B1): One apple in one year and (B2): Two apples in one year and one day.

If A1 over A2 is preferred stationarity would imply that B1 over B2 is preferred. However almost nobody chooses B1 over B2 whereas some people might prefer A1. This inconsistent behavior can't be explained by exponential discounting.

One way of dealing with this phenomena is by assuming a hyperbolic discount function with relatively high discount rates for outcomes in the near future and relatively low discount rates for distant outcomes (see for example Ainslie, 1975; Loewenstein and Prelec, 1992; Kirby and Marakovic, 1995; Frederick et al., 2002). Strotz (1955) was one of the first to analyze declining intertemporal discount rates in a theoretical framework. He showed that if discount rates are not constant, a planner will not stick to the optimal plan

3 The first experiments were conducted with pigeons (see for example Ainslie and Herrnstein, 1981) and the observed effects correspond with the effects observed later in human behavior. 
evaluated at some point in time t. This plays an important role in the literature dealing with self-control problems. People with low self-control put too much weight on the near future disregarding long-term costs and benefits. For example, DellaVigna and Malmendier (2006) find that most people plan to attend the gym on a regular basis when signing the membership contract, but actual attendance is much lower (for further evidence on self-control problems see DellaVigna, 2009; Beshears et al., 2011). One way to overcome these problems is to bind or precommit one's own behavior (see for example Strotz, 1955; Thaler and Shefrin, 1981; Laibson, 1997; Sorger, 2007).

Time preferences also seem to matter in many other economic and non-economic fields. For example, Meier and Sprenger (2010) find that people who behave as if they would discount payments hyperbolically are more likely to have credit card debt and to have higher amounts thereof. Meier and Sprenger (2012) find that hyperbolic decision makers participate less in financial literacy programs. Medical studies find that smokers have decreasing discount rates over time and therefore put too much weight on immediate rewards and costs even in tasks not related to smoking, see for example Bickel et al. (1999).

\section{Measuring time preferences}

In experimental economics choice based and matching based approaches are popular (see Hardisty et al., 2013). Choice methods ask participants in a set of questions to choose between a smaller earlier payment (or reward) and a later larger payment. Thereby the later payment is constantly increased or the earlier payment constantly decreased to find participants switching point, which is then used to calculate a lower and a upper bound for the discount rate. The matching approach in contrast directly asks for indifference points. Participants have to state which earlier payment would make them indifferent to later payments or vice versa. This has the advantage that not only an upper and lower bound but an exact discount rate can be calculated. Frederick et al. (2002) present a broad discussion of further advantages and disadvantages of these two methods. To test for hyperbolic discounting in both methods payments (the earlier and later) are delayed by the same amount of time. Declining discount rates for the delayed payments are treated as evidence of hyperbolic discounting. We follow the standard eliciting procedure in decision analysis literature (see for example Ahlbrecht and Weber, 1997; Sayman and Öncüler, 2009) ${ }^{4}$.

\section{Hypotheses}

In the following, four hypotheses are derived about how time preferences influence the annuitization decision. In the analysis, a decision maker who has to choose between a lump sum and an annuity is considered. The starting point is the expected present value (EPV) of the annuity. By definition the EPV of a fair an-

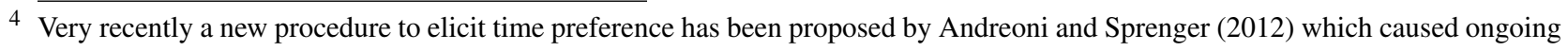
debate about (see Epper and Fehr-Duda, 2013; Drichoutis and Nayga, 2013) 
nuity equals the lump sum if the decision maker has exponential time preferences. This is compared to a decision maker who follows hyperbolic discounting. In this case the absolute EPV and also its change with the decision maker's age will be regarded ${ }^{5}$.

In the analysis two frameworks are used: the first case is called the "immediate case" where we take a look at immediate annuities, meaning that a decision maker has to decide between an annuity starting today and a lump sum also received today. The second case is the "deferred case". In this scenario the person faces the decision between an annuity starting at retirement age and a lump sum also received when entering retirement. To be precise, the deferred case looks at an immediate annuity starting at retirement age but being evaluated today by a $\mathrm{x}$ year old decision maker with $\mathrm{x}$ being less than retirement age.

\section{Discount functions}

To derive the hypotheses we assume a specific form of the hyperbolic function. In general, discount functions can be written as $D F=(1+i)^{-\alpha(t)}$ with $i$ being an interest rate and $\alpha(t)$ being a function that describes how time is perceived (see Ahlbrecht and Weber, 1997). For example, if time is weighted in a linear way and $\alpha(t)=t$ we arrive at the exponential discount function. In the following two further discount functions are considered. First, the Harvey (1986) discount function with $\alpha(t)=\frac{r}{\ln (1+i)} \ln (1+t)$ leading to $D F_{\text {Harvey }}(t)=(1+t)^{-r}$. Note that the Harvey function is a special case of the general hyperbolic function $D F=(1+\gamma t)^{-\frac{\alpha}{\gamma}}$ proposed by Loewenstein and Prelec (1992) with $\gamma=1$ and $\alpha=r$. Second, the quasi-hyperbolic discount function proposed by Phelps and Pollak (1968) and Laibson (1997) with $\alpha(t)=t+\frac{\ln \left(\frac{1}{\beta}\right)}{\ln \left(1+i_{Q}\right)}$ and therefore $D F_{Q H B}=\beta\left(1+i_{Q}\right)^{-t}$. Figure 1a graphs the exponential function, the Harvey function and the quasi-hyperbolic function. In this example an interest rate of $i_{E X P}=4.5 \%$ is chosen $^{6}$. The parameter $r$ is calculated in such a way that the hyperbolic and exponential function assign the same weight to period 15. For the quasi-hyperbolic function $\beta=0.7$ and $i_{Q}=2.04 \%$ are chosen to also assign the same weight to period 15, see Laibson et al. (2003). It can be seen that both the Harvey and the quasi-hyperbolic function lead to stronger discounting in earlier periods compared to the exponential function. Therefore, hyperbolic decision makers are often described as present biased as they have a strong preference for immediate outcomes.

Figure $1 \mathrm{~b}$ presents the values for the functions $\alpha(t)$. Discounting exponentially implies $\alpha(t)=t$. Also, the quasi-hyperbolic function leads to a linear function $\alpha(t)$ for $t>0$. Only the Harvey function leads to a non-linear weighting of time as in this case $\alpha(t)$ is a logarithmic function. This implies that, e.g., the time

5 Introducing risk aversion would lead to a preference for the annuity (for the EU-maximizer) and would make the annuities more preferable for the hyperbolic decision maker. However, we base the formal analysis on risk neutrality as we are primarily interested in the effect of time preferences. We elicit risk preferences in the survey and control for them in the empirical analysis.

$64.5 \%$ is used as this is the average return German insurance companies yielded on their assets in the last 10 years (2002 - 2012). 
difference between period 4 and 5 is weighted larger than the difference between periods 14 and 15 . As the decision whether to take a lump sum or an annuity also affects the very distant future this feature of the Harvey function is especially useful for our analysis. Abdellaoui et al. (2010) test the validity of different discount functions and find that the Harvey (1986) model fits their data best. Therefore, we use the Harvey (1986) approach with $D F_{H B}(t)=(1+t)^{-r}$. The exponential function is defined as $D F_{E X P}(t)=(1+i)^{-t}$ with $i$ being the interest rate.

\section{Hypothesis 1}

\section{a) Immediate case}

We consider an immediate annuity that pays a yearly amount of y and a decision maker who has to choose between this annuity and a lump sum A (paid out immediately). Let $p(x+t \mid x)$ be the probability of an $x$ year old person being alive after $t$ additional years. Assuming for the purpose of simplicity that the maximum age is 120 leads to $p(x+t>120 \mid x)=0, \forall x$. Discounting future annuity payments exponentially with interest rate $i$ leads to the following expected present value of the immediate annuity:

$$
E P V_{E X P}(x)=y(x) \sum_{t=0}^{120-x} p(x+t \mid x)(1+i)^{-t}
$$

If the annuity is fair the EPV of the annuity equals the lump sum ${ }^{7}$. Therefore:

$$
y^{\text {fair }}(x)=\frac{A}{\sum_{t=0}^{120-x} p(x+t \mid x)(1+i)^{-t}}
$$

Now consider an investor who discounts future payments hyperbolically. The EPV of the fair annuity is:

$$
E P V_{H B}(x)=A \frac{\sum_{t=0}^{120-x} p(x+t \mid x)(1+t)^{-r}}{\sum_{t=0}^{120-x} p(x+t \mid x)(1+i)^{-t}}
$$

We compare the expected present value of the annuity, following hyperbolic discounting, with the lump sum payment $A$. Figure 2a displays the difference $D(x)=E P V_{H B}(x)-A$ for $x \in[0,1, \ldots, 66]$, three hyperbolic parameters and a lump sum payment of $A=100,000$ EUR. The maximum age $x$ for which $D(x)$ is calculated is 66 .

The graph shows that for all parameters $r$, the relation between the decision maker's age and the difference of the $E P V_{H B}$ of the annuity and the lump sum is negative. As the lump sum payment is constant, this implies a decreasing $E P V_{H B}$ with age. For example, the difference between the $E P V_{H B}$ of the annuity and the lump sum for a 20-year old hyperbolic decision maker is about 33,000 EUR (for $r=0.2381$ ), in favor of the annuity. If the same decision is made 46 years later at the age of 66 , the difference shrinks

7 For the derivation of all hypotheses fair annuity payments $y(x)^{\text {fair }}$ are assumed. Using actuarial unfair monthly payments $\varphi y(x)^{\text {fair }}$ with $\varphi \in(0 ; 1)$ only scales all annuity payments by the factor $\varphi$ but does not change the hypotheses. 
by 43,000 EUR to about $-10,000$ EUR, leading the decision maker to now prefer the lump sum. Note that for exponential time preferences $D(x)=0$ for all $x$. The critical age at which the difference $D(x)$ becomes negative depends on the parameter $r$. For larger parameters the critical age gets smaller (see figure 3). For example, if $r=0.3841$ it holds that $D(0)=0$ and $D(x)<0$ for all $x>0$. Abdellaoui et al. (2010) estimate different discount functions and find a hyperbolic parameter of $r=0.19$. For this parameter the critical age is at about 64 years. Figure $2 b$ presents the change in $\mathrm{D}(\mathrm{x})$ for a one-year increase in the decision maker's age, calculated as $\Delta D(x)=D(x+1)-D(x)$. The changes are always negative for the relevant ages and therefore the expected present value of the fair annuity declines with age, leading to hypothesis $1(\mathrm{a})$ :

Hla: The decision maker's age has a negative effect on the attractiveness of fair, immediate annuities.

The intuition behind this hypothesis is as follows: hyperbolic discounting leads to undervaluation of earlier payments and overvaluation of later payments (compared to exponential discounting). Older decision makers expect less later payments than young decision makers, simply due to a shorter remaining lifetime. Therefore, older hyperbolic decision makers overvalue fewer expected payments and the annuity seems unattractive to them.

\section{b) Deferred case}

In the deferred case, the decision maker has to decide today between an annuity starting at the age of 66 (retirement age) and the corresponding fair lump sum also received at the age of 66. Using equation (2) the fair annuity payment conditional on reaching the age of 66 is:

$$
y^{\text {fair }}(66)=\frac{A}{\sum_{t=0}^{(120-66)} p(66+t \mid 66)(1+i)^{-t}}
$$

For exponential discounting, the EPV of the annuity for an $x$-year old investor is:

$$
E P V_{E X P}(x)=y \sum_{t=0}^{(120-66)} p(66+t \mid 66)(1+i)^{-(t+66-x)}
$$

Now consider a decision maker who follows hyperbolic discounting. The EPV of the annuity is:

$$
E P V_{H B_{\text {annuity }}}(x)=A \frac{\sum_{t=0}^{(120-66)} p(66+t \mid 66)(1+(t+66-x))^{-r}}{\sum_{t=0}^{(120-66)} p(66+t \mid 66)(1+i)^{-t}}
$$

To compare $E P V_{H B_{\text {annuity }}}(x)$ with the lump sum, the EPV of the lump sum is calculated:

$$
E P V_{H B_{\text {lumpsum }}}(x)=\frac{A}{(1+(66-x))^{r}}
$$

Figure 4a displays the difference $D(x)$ between $E P V_{H B_{\text {annuity }}}(x)$ and $E P V_{H B_{\text {lumpsum }}}(x)$ for $x \in[0,1, \ldots, 66]$, three hyperbolic parameters and a lump sum payment of $A=100,000$ EUR. Figure $4 \mathrm{~b}$ shows the change 
in this difference for a one-year increase of age $x$. We find constant or slightly increasing differences in expected values for a one year increase in age for young people and a strong decline for older people (figure 4a). Also, here the difference is positive in most cases and only becomes negative if the decision makers' age is close to 66. Note that a 66 year old decision maker faces the same decision as presented in the immediate case, as for him the first annuity payment or the lump sum payment is received immediately. As already indicated in figure $4 \mathrm{a}$, the change in $D(x)$ (figure $4 \mathrm{~b}$ ) is initially slightly positive but becomes negative towards the end ${ }^{8}$.

H1b: The decision maker's age has a negative effect on the attractiveness of fair, deferred annuities.

\section{c) Immediate vs. deferred framework}

Hypothesis 1(c) takes into account that the exact form of the discount function decision makers use to evaluate future outcomes is unknown. So far we just know that hyperbolic discounting should make annuities appealing for young people and unattractive for older ones. The change in the immediate case for a one unit increase of age is always negative (Figure 2b); but for the deferred case we have a slightly positive change for ages 0 to about 50 - 60 and a strong negative change beyond that age level (Figure 4), which leads to:

HIc: Decision maker's age has no negative effect on the annuitization decision in the deferred case for a sample consisting only of participants with age $<50$.

\section{Hypothesis 2}

According to the definition of the annuity, the age effect should be prevalent for participants that behave time inconsistent. This should be true for the immediate and the deferred case:

H2: Decision maker's age only has a negative effect for a sample consisting of time inconsistent participants and no effect for time consistent participants.

\section{Survey design and summary statistics}

\subsection{Survey design}

To test the hypotheses developed in section 3 an online survey was conducted in cooperation with the "Frankfurter Allgemeine Zeitung (FAZ)" which is one of the biggest daily newspapers in Germany. The FAZ promoted our survey in the print edition and posted a link on their online portal. To avoid biasing potential participants, the FAZ agreed to only promote and post the link and to write an article about the topic after the

8 The positive change cannot be seen in figure $4 \mathrm{~b}$ as $\Delta D(x)$ is only slightly above zero. 
study was finished. 3,077 participants with age ranging from 18 to 86 completed the survey in on average 11 minutes. Participants were asked to make hypothetical choices about retirement planning and to answer a set of questions regarding their time preferences, demographics and some additional control questions. In particular, the survey asked participants to choose between a monthly payment (annuity) and a lump sum in two different scenarios: in the immediate case, subjects chose between a lump sum paid out today and a fair annuity also starting today. In the deferred case, participants chose between an annuity starting at retirement age and a lump sum also received when entering retirement. Each participant was randomly assigned to one of the two scenarios. In a further question he/she had to choose an annuitization rate between $0 \%$ and $100 \%$ in steps of $10 \%$.

\section{Retirement scenario}

The retirement scenario was designed to test the deferred case. Participants were asked: "Imagine you are at age 66 and plan to retire this year. Your retirement account has a balance of EUR A to which you now have access to. There are two ways to withdraw the money." Option 1 was a lump sum payment and participants were told that they will receive the whole account balance on retirement. Option 2 was a fair annuity and participants were told that option 2 guarantees a monthly payment of EUR y as long as they are alive. We randomly varied the amount A between subjects from EUR 100,000 to EUR 1,000,000 in five steps and calculated EUR y as the fair monthly annuity at age 66 with respect to gender assuming a constant interest rate of $4.5 \%$. Table 1 shows the payout options for the five different amounts of A. After participants made their decision we changed the possible payout options in a consecutive question. Now participants could determine annuitization rates in $10 \%$ steps from $0 \%$ to $100 \%$. The amount A remained the same as in the previous question and participants could always see to what payouts their decision would lead.

\section{Lottery scenario}

The lottery scenario tests the immediate case. Participants are asked the same two questions as explained above with two important differences. 1) They are told that they won an amount of A in the national lottery today and that they have to choose the payout scheme. The major difference here is that the payments in this scenario start immediately (and not at age 66). 2) To calculate the fair annuity gender, an interest rate of $4.5 \%$ and the actual participants' age is used. Therefore 83 different fair annuities (for ages 18 to 100) per gender are calculated. Note that the lottery and retirement scenario presented the same situation for participants at age 66. We again varied A between subjects from EUR 100,000 to EUR 1,000,000 in 5 steps.

9 This implies that an annuitization rate of $60 \%$ corresponds to $60 \% * \mathrm{y}$ paid out every month and $40 \% * \mathrm{~A}$ being paid out as a lump sum. 


\section{Retirement vs. lottery scenario}

The two scenarios differ in the point in time at which payments are received and in the wording. In the immediate case the word "lottery" is used, whereas in the deferred case we use the word "retirement". To test the effect of differences in wording, we consider a subsample of participants with an age close to 66 (see section 5). Besides wording, for these participants there is almost no difference between the immediate and the deferred case as payments in the latter case start at age 66.

\section{Time preferences}

As stated earlier, there is no clear evidence which method of eliciting time preferences leads to the best results. Therefore we choose a procedure that is as simple as possible but allows to distinct between subjects that behave time consistent and subjects that are time inconsistent (see Harrison et al., 2002; Ifcher and Zarghamee, 2011; Meier and Sprenger, 2012). In a choice-based task, participants had to decide between a tax refund $\mathrm{T}$ that is obtained earlier and a refund $\mathrm{T}(1+\mathrm{i})$ that is obtained later in time. In three questions the earlier payment is received immediately and the later one is received in 10 months with $i=3.3 \%, 11.3 \%$ and $31.3 \%$. The second set of questions uses the same interest rates with the difference that all payments are shifted 18 months into the future (earlier payment in 18 months, later in 28 months). If participants have time consistent preferences only the difference between the two payments (10 months for all questions) should matter and for each interest rate the decision between the earlier or later payment should be the same. All six questions are displayed on the same screen, put in a pair-wise manner together (paired by interest rate) and participants are made aware of the fact that there are no right or wrong answers.

For the survey we used hypothetical choice questions. There are two reasons for this: 1) using real money choices can lead participants do consider future payments as uncertain and therefore a present-bias or hyperbolic discounting pattern can be generated even for subjects with time consistent preferences (see for example Read, 2005; Sutter et al., 2013) 2) real stakes can also cause a self-selection problem. If real money is paid it could be that subjects that are in need of immediate money are attracted and results are biased in the direction of hyperbolic discount (see Noor, 2009; Sutter et al., 2013).

In addition to the tax refund questions participants also had to agree on a seven-point Likert scale ( $1=$ fully disagree to $7=$ fully agree) to the following statement on a previous page: "I'm an impatient person".

\section{Controls}

We use participants self-reported loss and risk attitude to proxy for loss and risk aversion. Earlier studies find that self-reported risk attitude on a Likert scale is a good predictor of actual risk taking (see e.g. van Rooij et al., 2011; Nosic and Weber, 2010). On a seven-point Likert scale participants have to agree to 
the statements "I'm a risk averse person" as a measure for risk aversion and "I'm very afraid of losses" as a measure of loss aversion.

To elicit a financial literacy score, participants answer six questions. We choose one of the basic questions from Lusardi and Mitchell (2007), three advanced questions from van Rooij et al. (2011) and develop two more complicated questions on our own. We do so because the FAZ newspaper has a focus on financial markets and previous studies find that subjects, with similar characteristics are remarkable financially literate. (see Mueller and Weber, 2011).

One of the most important factors that influences the annuitization decision should be individuals' subjective life expectancy. The method of the Survey of Consumer Finances and Mirowsky (1999) is adopted. Participants are asked (directly) to think about their life expectancy and give an estimate thereof.

In addition participants indicate at what age they plan to retire, if they own private pension insurance and how they rate the certainty of social security benefits guaranteed by the government today.

\subsection{Summary statistics}

Table 2 displays summary statistics on subjects annuitization decision, demographics, time preferences and controls. We excluded subjects with age above 66 as in the later analysis only participants up to that age are considered ${ }^{10}$. More than half of the participants (57\%) choose the annuity in the simple $0 / 1$ framework and the average person chooses an annuitization rate of $56 \%$. The option to partially annuitize makes annuities more attractive as for this question almost $80 \%$ of participants choose to annuitize at least to some extend, confirming Beshears et al. (2012). The average age is about 42 years (median 43) and participants are between 18 and 66 years old. Men are overrepresented in our study (83\% male) reflecting the fact that the majority of FAZ readers are male (62\%) and that men are more likely to participate in online surveys of our kind (see Mueller and Weber, 2011). Subjects report a relatively high after tax income of about EUR 3,400 (median 3,000) per month (compared to a German average after tax income of about EUR 1,470 in $2011^{11}$ ) and are well educated with $91 \%$ having received the German equivalent to a high school diploma and $66 \%$ having graduated from a university. Half of the participants are married.

Given a fixed interest rate, peoples' choices are defined as inconsistent if they choose the earlier payment in the today-setting and the later payment in the 18-month-setting. Depending on the interest rate (3\%, $11 \%$ or $31 \%$ ), between $18 \%$ and $25 \%$ of participants made an inconsistent decision of which about $7 \%$ of participants always chose inconsistently. The self-reported impatience score is measured on a 1 to 7 Likert scale. The correlation between self-reported impatience and the number of time inconsistent answers to the tax refund questions is surprisingly only about .03 (not significant).

${ }^{10}$ Also 2 participants which were younger than 66 but have already been retired are excluded.

${ }^{11}$ Source: German Federal Statistical Office 2012 
Asking participants about their risk- and loss aversion on a 1 to 7 Likert scale leads to an average of 3.90 and 4.30 respectively. As expected, participants did extremely well in standard financial literacy questions with on average 3.49 / 4 correct answers. Introducing the two more difficult questions helped to separate the sample as subjects answered only 0.59 / 2 questions correctly. Directly asking participants about their subjective life expectancy leads to estimates which, with an average of 83.29 years for male participants, are above the objective life expectancy and, with 83.87 for female participants, are close to the objective life expectancy $^{12}$. The average planned retirement age of about 65 is close to the actual retirement age in Germany.

\section{Survey - results and robustness}

\subsection{Results}

\section{HIa and HIb: Annuitization by age - full sample}

In the following analysis we investigate the immediate case (lottery scenario) as well as the deferred case (retirement scenario). One might be concerned that possible differences arise as a consequence of the different wording in the two scenarios ("lottery" vs. "retirement"). For participants with an age close to 66 the only difference between the two cases is the wording ("lottery" or "retirement"). Table 3 presents results for a logistic regression with participants choice in the $0 / 1$ framework (1=annuity, $0=$ lump sum) as dependent variable and age(c), a scenario dummy ( $0=$ lottery, $1=$ retirement) and the interaction between age(c) and scenario as explanatory variables. The analysis is restricted to participants with an age between 61 and 66. The variable age(c) is the mean-centered age of participants in this subsample. Centering the age variable is necessary as otherwise the null effect of the scenario dummy would be the effect for age equal to zero (see Irwin and McClelland, 2001; Spiller et al., 2013). The interaction coefficient and t-value are calculated based on Norton et al. (2004). Neither the scenario nor the interaction of age and scenario have a significant effect on the annuitization decision in this subsample.

Table 4 presents results of two logistic regressions where the dependent variable again is a dummy that equals 1 if subjects chose the annuity and 0 if they chose the lump sum in the 0/1 framework. Column 2 and 3 present results for participants in the lottery scenario (immediate case) and columns 4 and 5 present results for the retirement scenario (deferred case). For both scenarios coefficients and odds ratios are reported. An odds ratio above one can be interpreted as the factor by which the probability of choosing the annuity increases for any person. For negative coefficients and corresponding odds ratios below one the inverse odds ratio is used to interpret the effect ${ }^{13}$. In both scenarios the negative effect of age is highly significant and

\footnotetext{
12 The average male participant in our sample is 43.61 years old, the average female participant is aged 40.14 years old. Using the latest German life tables a 43.61 year old German male on average lives until the age of 78.76 and a 40.14 year old German female on average lives until the age of 83.19 .

${ }^{13}$ For example, if person $\mathrm{X}$ has a $50 \%$ probability of choosing the annuity, an odds ratio of 1.05 translates to an increase of that
} 
economically strong with coefficients of -0.028 and -0.019 , respectively. To understand the magnitude of this effect the inverse odds ratio of the age coefficient in the lottery scenario is calculated as $\frac{1}{0.972}=1.0288$. This implies that the probability of choosing the lump sum increases by $2.88 \%$ per year. Note that this effect is constant and not dependent on values of the other explanatory variables. In the retirement case the effect is slightly weaker with an inverse odds ratio of 1.0194 translating to an increase in probability of choosing the lump sum by $1.94 \%$ per year. The age coefficients in the lottery and retirement scenario are not significantly different. In both scenarios older participants tend to choose the lump sum whereas younger participants prefer the annuity. Therefore, the main hypotheses 1(a) and 1(b) are confirmed, see also Brown et al. (2012) and Shu et al. (2013) who find negative age effects using Croatian pension and survey data. In both scenarios all other demographic variables are insignificant.

In the lottery scenario, people who make time inconsistent decisions (Always Inconsistent $=1$ ) are less likely to choose the annuity. With a coefficient of -0.670 and an inverse odds ratio of 1.95 for a discrete change from zero to one the effect is particular strong. This makes intuitive sens, as always inconsistent means a strong present bias, which directly relates to preferring the lump sum. Therefore, the negative effect supports hypotheses 1. Compared to the base case, being inconsistent once or twice, participants who behave always time consistent (Always Consistent $=1$ ) have a stronger preference for the lump sum. This is in line with our previous analysis (see figure 2a) as being hyperbolic increases the preference for annuities (unless for subjects around retirement age).

In the lottery scenario 4 out of 9 controls are significant. The more risk averse participants are, the more likely they are to insure against longevity risk by choosing the annuity. Also, Brown (2007) states that loss aversion could be a reason for low annuitization rates if people see the annuity as a risky gamble. The effect for loss aversion is negative but not significant. Financial literacy is measured by the number of correct answers to questions 1 to 5 and by a dummy that equals 1 if the participant gave the correct answer to question 6 and 0 otherwise. The financial literacy 1-5-variable has a significant positive effect on the annuitization decision indicating that participants who are more financially literate are more likely to choose the annuity. However, participants who gave the right answer to a question regarding the CAPM (question number 6) tend to choose the lump sum. It could be that these participants are active and knowledgeable in the stock market and expect a higher return than the return implied by the annuity. Also, the effect of the subjective life expectancy is highly significant. Participants who expect to live longer choose the annuity. With an odds ratio of 1.045 , meaning the probability of choosing the annuity increases by $4.5 \%$

probability by $5 \%$ per one unit increase (for example from age $=51$ to age $=52$ ) in the independent variable: $50 \% * 1.05=52.5 \%$. An odds ratio below one can be interpreted as an increase of the probability of choosing the lump sum. If person Y has a $50 \%$ probability of choosing the lump sum, an odds ratio of 0.90 implies an increase of that probability by $(1 / 0.9-1)=11.11 \%$ per one unit increase in the independent variable: $50 \% * 1.11=55.55 \%$. 
per additional year the participant expects to live longer, this finding is also economically meaningful. In contrast to the lottery scenario, neither risk aversion nor loss aversion and financial literacy prove to be significant in the retirement scenario. However, owning private pension insurance leads to the tendency to favor the annuity. One could expect that demand for annuities decreases because in this case the annuity could be crowded out by already existing private annuitization (see for the crowding out argument Mitchell and Moore, 1998; Dushi and Webb, 2004; Purcal and Piggott, 2008). Nevertheless, owning private pension insurance seems to proxy more for participants who have a general preference for insurance against longevity risk.

The magnitude of payments only seems to matter in the retirement scenario. For high payments (lump sum $=$ EUR 750,000 or EUR 1,000,000) participants indicate that they would prefer the lump sum when they retire ${ }^{14}$. Other studies find that an increase in magnitude leads to a decrease of exponential discount rates of participants (see for example Loewenstein and Prelec, 1992; Baucells and Heukamp, 2012). Therefore, one could expect a positive influence on the probability of choosing the annuity. However, it is not clear in what way an increase of magnitude influences discount rates of hyperbolic decision makers. Future research is needed to answer this question.

Relatively low payments (lump sum and annuity) compared to participants monthly income ( $\frac{\text { income }}{\text { lumpsum }}>$ $5 \%)$ and the time needed to answer the survey have no significant effects on the annuitization decision.

H1c: Annuitization by age - lottery vs. retirement scenario

The third hypothesis refers to participants with an age below 51 and the differentiation between the retirement and lottery scenario. Figure $2 \mathrm{a}$ and figure $4 \mathrm{a}$ show that for immediate annuities (lottery scenario) the expected present value of the annuity declines monotonically in the age of purchase. In the deferred case (retirement scenario) a small increase of the expected present value for ages 0 to 50 and a following strong decline is observed (here the age is not the age of purchase but the age at which the annuity that starts at 66 is evaluated). Therefore, in a subsample of participants aged below 51, the negative age effect should only be present in the lottery scenario. Table 5 presents results of two logistic regressions.

Including time preferences, controls and magnitude controls leads to a significant age effect in the lottery scenario (immediate case). Starting with columns 2 and 3 of table 5, an age coefficient of -0.038 is observed which is, in absolute terms, also higher compared to the full sample coefficient of -0.028 . In the retirement scenario the age coefficient is insignificant. The difference between the lottery and retirement scenario is significant at the $10 \%$-level (one sided test, t-value of -1.60) and therefore hypothesis $1 \mathrm{c}$ is

\footnotetext{
14 Taking into account the question about the annuitization rate we find that the absolute annuity payment increases in magnitude, even if the annuitization rate decreases. We find that the relation between the magnitude of the lump sum and the absolute magnitude of the annuity is positive yet decreasing (concave) in magnitude. Therefore, it could be that in the 0/1-framework higher magnitudes lead to a preference for the lump sum as partial annuitization is not possible.
} 
confirmed. In both subsamples life expectancy and financial literacy are significant, whereas risk aversion now only is significant in the lottery scenario.

\section{H2: Annuitization by age - time consistent and inconsistent participants}

In section 2 of this paper the prediction was made that there is an age effect on the annuitization decision for time inconsistent participants and no effect for participants who behave time consistent (hypothesis 2). To test this hypothesis two different methods are used. First, the sample is split into time consistent and time inconsistent participants and it is further analyzed whether the age effect is present in only the time inconsistent subsample. Second, using the tax refund questions, a range for the hyperbolic parameter $\mathrm{r}$ is calculated for each participant. It is then analyzed in which way the size of the parameter $\mathrm{r}$ influences the annuitization decision. We start by discussing the results of the first method:

To test hypothesis 2 the sample is split according to the answers participants gave regarding six tax refund questions. Subsample one includes only participants who chose in a time inconsistent manner in at least two of the three cases (time inconsistent group). The second subsample consists of participants who gave consistent answers in at least two of the three cases (time consistent group). For this analysis both scenarios (lottery and retirement) are pooled. We do so as a negative age effect is observed in both scenarios (see table 4). Hypothesis 2 refers to the difference between time consistent and time inconsistent participants. This difference should not only be prevalent in both scenarios, but it should also have the same effect on the age coefficient in both scenarios. Table 6 presents logistic regression results for demographic variables, controls and scenario controls. Time preference variables are excluded from the analysis as they are used to split the sample. Columns 2 and 3 present coefficients and odds ratios for the time inconsistent group and columns 4 and 5 for the time consistent group, respectively.

In both subsamples we find a negative and significant effect of age. However, the coefficient for the inconsistent group is, in absolute terms, about two times stronger. The effect measured by the inverse odds ratio for the inconsistent subsample is also almost two times as strong compared to the consistent subsample (inverse odds ratio 1.032 vs. 1.017). A possible risk-based explanation for the significant age effect in the time consistent subsample is given in section 5.3 of this paper in which uncertainty of lifespan is proxied by the variance in subjective life expectancy. In summary, a strong and significant negative age effect on the probability of choosing the annuity is obtained (table 4), with this effect becoming stronger for "hyperbolic" participants and weaker for "less hyperbolic" ones (table 6).

Additional variables of interest are financial literacy and life expectancy. In the inconsistent sample financial literacy and life expectancy have the same strong and significant effect as observed before. For the latter this is also true in the consistent subsample. Surprisingly, financial literacy only seems to affect time inconsistent participants as it has no effect in the second subsample. However, comparing financial literacy between the two subsamples shows that the number of correct answers is significantly higher in the 
time consistent group (difference of 0.34 , significant at the $1 \%$-level), resulting in a $20 \%$ lower variance of correct answers. This could explain why the positive effect of financial literacy is not observed in this subsample.

The second method to test hypothesis 2 is to calculate a range of the hyperbolic parameter $\mathrm{r}$ for each participant using the tax refund questions. For example answering the first pair of tax refund questions inconsistently means that the participant prefers a tax refund of EUR 1,100 today over a refund of EUR 1,130 in ten months, but he/she also prefers a refund of 1,130 in 28 months over a refund of 1,110 in 18 month. Therefore $1,100 \geq \frac{1,130}{\left(1+\frac{10}{12}\right)^{r}}$ and $\frac{1,100}{\left(1+\frac{18}{12}\right)^{r}} \leq \frac{1,130}{\left(1+\frac{28}{12}\right)^{r}}$. This results in $0.0444<r<0.0935$. Answering the second (third) pair of tax refund questions inconsistently results in $0.1436<r<0.3025(0.3741<r<0.7883)$. A problem of this method is that only participants that answer exactly one pair of tax questions inconsistently can be taken into account. Answering more than one question inconsistently results in multiple, incompatible conditions for the parameter $\mathrm{r}^{15}$. This problem arises due to our survey design which was intended to separate time inconsistent participants from time consistent ones. In general, there are more elaborate methods of eliciting parameters of specific discount functions (see for example Abdellaoui et al., 2010; Andreoni and Sprenger, 2012; Hardisty et al., 2013). Overall 595 participants answer exactly one question inconsistently.

It is now considered how changes in $\mathrm{r}$ influence the expected present value of the annuity. It is easy to show that the first derivative of the difference between the expected present value of the annuity and the lump sum payment, i.e. $D(x)=E P V_{H B}-A$, with respect to $r$ is negative (see also Appendix A.1). For higher values of parameter $r$ the annuity becomes less attractive. In the deferred case the sign of the derivative depends on the parameter $r$. Therefore, the effect of changes in $r$ is tested in a subsample consisting of participants assigned to the lottery scenario (immediate case) that answered exactly one tax refund question inconsistently. This results in $\mathrm{N}=291$ observations.

Column 2 of table 7 presents results of a logistic regression with the annuity choice in the 0/1 framework as the dependent variable. Due to limited degrees of freedom in all regressions presented in table 7 , only control variables that have been significant in earlier regressions (see table 4) are included. Table 7 shows a highly significant age effect in the (full) subsample with a coefficient of -0.033 . Also, the financial literacy question 6 (CAPM) and life expectancy have a significant influence on the annuitization decision. Two dummy variables (parameter $r$ medium, parameter $r$ large) indicate a medium (large) parameter $r$ (equals one if the answer to the second (third) pair of tax refund questions is inconsistent). Both coefficients of the dummy variables have the expected sign. The larger the parameter $r$ is, the lower the expected present value of the annuity as well as the probability of choosing the annuity. The effect is significant at the $10 \%$ -

\footnotetext{
15 To our surprise this issue receives not much attention in the literature using the choice approach. Note that the incompatibility also arises for quasi-hyperbolic discounting.
} 
level for large parameters. With an inverse odds ratio of 1.8897 the effect is also economically meaningful, confirming the idea that the previous results are driven by hyperbolic discounting.

Besides the effect of a change in $\mathrm{r}$ on $D(x)$, also the effect on $\Delta D(x)=D(x+1)-D(x)$ is considered. Appendix A.2 shows the derivative of $\Delta D(x)$ with respect to $\mathrm{r}$ for the immediate case ${ }^{16}$. It can be seen that for relevant values of $i, x$ and $r$ the derivative is positive indicating that an increase in $r$ results in an increase in $\Delta D(x)$. This also means that the (negative) difference between $D(x+1)$ and $D(x)$ gets smaller. If the previous results are caused by hyperbolic discounting of participants, a smaller difference between $D(x+1)$ and $D(x)$ should result in a weaker age effect. To test this the subsample of 291 participants is split into three smaller subsamples using the size of parameter r. Columns 3, 4 and 5 of table 7 present logistic regression results for a subsample of participants with $r$ being small (column 3), medium (column 4) and large (column 5). A significant negative effect of age is present in the first two subsamples even if only $\mathrm{N}=95$ and $\mathrm{N}=125$ observations are taken into account. As predicted, the coefficient of the age variable gets less negative and less significant for an increase in $\mathrm{r}$ (coefficient of $-0.060^{* * *}$ for $\mathrm{r}=$ small, compared to $-0.034^{* *}$ for $\mathrm{r}=$ medium and -0.029 for $r=$ large). The difference between the coefficients for $r=$ small and $r=$ large is significant at the $1 \%$-level (one-sided t-test) confirming previous results.

\subsection{Robustness}

\section{Annuitization rate}

To test the robustness of the results presented above, the annuitization rate question is used as the dependent variable. Participants indicate which fraction of the lump sum they want to annuitize (in steps of $10 \%$ ). Figure 5 shows that in both scenarios more than $50 \%$ of participants either choose full annuitization $(25.96 \%$ in the lottery scenario $=$ immediate case, $18.84 \%$ in the retirement scenario $=$ deferred case), the $50 / 50$ choice $(12.81 \%$ in the lottery scenario, $13.77 \%$ in the retirement scenario) or zero annuitization ( $22.52 \%$ in the lottery scenario, $20.14 \%$ in the retirement scenario). In between, annuitization rates of more than $50 \%$ are popular. This could indicate that people have some immediate use for a larger sum (e.g., repaying debt or buying a new car) but still want to annuitize most of the lump sum.

Table 8 presents coefficients and standard errors of two OLS regressions with the annuitization rate as the dependent variable. Columns 2 and 3 report results for the lottery scenario, columns 4 and 5 for the retirement scenario. Most effects found in the previous analysis ( $0 / 1$ framework) are confirmed. In both scenarios age has a negative effect on the annuitization rate, however now the effect is only significant in the lottery scenario. On average, being one year older decreases the annuitization rate in the lottery scenario (retirement scenario) by $0.4 \%$ points $(0.1 \%$ points). Also, time preference matters in the lottery scenario.

\footnotetext{
${ }^{16}$ The deferred case is not considered as the sign of the first derivative of $\Delta D(x)$ depends on the parameter $\mathrm{r}$. Again we have no clear hypothesis regarding how an increase of $\mathrm{r}$ influences $\Delta D(x)$.
} 
Participants who answered all tax refund questions inconsistently (Always Inconsistent $=1$ ) annuitize on average $11.0 \%$ less. The main hypotheses concerning the age and time preferences effects are confirmed.

\section{Variance analysis}

As a second robustness check the variance of the annuitization rate by age is taken into account. As the exact form of the hyperbolic discount function for each person is unknown, the exact critical age at which the lump sum becomes more attractive than the annuity cannot be calculated. Consequently, the impact of a hyperbolic discount function should be clear for old and young participants. Young individuals should prefer the annuity; old individuals should prefer the lump sum, (more or less) independent of the exact form of the discount function. For middle aged people the effect is not that clear, as it depends on the exact form of the discount function. This also means that younger and older people as a group should act more uniformly in their decision regarding the annuitization rate. Young people choose a high rate, whereas old people prefer a low rate. Middle aged participants decisions, however, should vary more strongly as someone might have a strong hyperbolic function, while others may only have weak hyperbolic functions. Therefore, the variance of the annuitization rate by age should have an inverted U-form. In particular, this should be true for the lottery scenario as here the expected present value monotonically decreases with age. For the retirement scenario the effect should be weaker as there should be no influence of age on the annuitization decision for participants below an age of 50. Figure 6 shows the variance of the annuitization rate for all age groups from 18 to 66 , for both scenarios. The solid line represents fitted values from a linear regression model with age and age squared as explanatory variables. An inverse U-shape can be seen in both scenarios. Also, the effect is stronger in the lottery scenario. Coefficients for age and age squared are highly significant (not reported) with $R^{2}$ of 0.2451 in the lottery scenario and only 0.0340 in the retirement scenario. This pattern supports the idea of hyperbolic discounting leading to the observed effects.

\subsection{Additional explanation: uncertainty about lifespan}

In section 5.1 a (small) negative age effect for the subsample of participants who make time consistent decisions is observed. This finding can't be explained by hyperbolic discounting. A possible explanation could be the uncertainty about one's lifespan. Older individuals may be more certain about their future lifespan ("I know how many cigarettes I've smoked in my life") compared to younger ones. As a result, young people might value the insurance feature of the annuity more even if they behave in a time consistent way. To test this, the variance of the subjective life expectancy by age is considered as a proxy for the uncertainty of future lifespan. We find that the average subjective life expectancy is almost constant over age but the variance is decreasing. Figure 7 shows the variance of the life expectancy by age and fitted values of an OLS regression with age and age squared as independent variables. The variance clearly declines with age; both coefficients (age and age squared) are negative and highly significant (not reported). These results are 
in line with Hamermesh (1985) and Mirowsky (1999) who also find a decreasing variance of subjective life expectancy with increasing age. Therefore, some part of the negative age effect found in the previous analysis might not be driven by hyperbolic discounting but by a higher uncertainty of younger participants expected lifespan.

\section{Commitment and policy implications}

The findings in section 5 of this paper suggest that real life annuitization could be increased by introducing a commitment device that allows people to bind their behavior. For this consideration the results of the deferred case (retirement scenario) are particular interesting. Here participants seem to make the optimal decision (according to expected utility theory) by choosing the annuity when thinking about what they would do in the future but reverse that decision once the day of the actual decision has arrived. If policy makers are interested in increasing real life annuitization rates they could use a simple commitment device, which allows people to undertake a binding annuitization decision earlier in life. This could also result in the reduction of adverse selection problems. Real life annuities pay only about $80 \%-90 \%$ of the fair annuity value (see Mitchell et al., 1999; Murthi et al., 2000). Part of this deduction is due to adverse selection in the annuity market (Finkelstein and Poterba, 2004). If potential annuity buyers have more information about their own life expectancy (e.g. strong smoker, medical history of family members, etc.) the annuity seller cannot use standard life tables to calculate prices. This information asymmetry is higher if the annuitization decision is made close to retirement and therefore close to the start of annuity payments. However, if people would be able to make a binding decision earlier in life the information asymmetry would be reduced because the annuity buyer would have less information about his/her future condition. Therefore the annuity seller could offer annuities closer to the fair value. This creates an incentive for people to bind their behavior and stick to the optimal decision.

\section{Conclusion}

This paper relates the effect of inconsistent time preferences to the choice between a lump sum payment and a monthly payment. Conducting a large online survey in cooperation with a major German newspaper, this study shows that young individuals have a preference for annuities whereas older individuals tend to prefer lump sum payments. In this study participants are assigned to two different frameworks. In the immediate case participants choose between a fair immediate annuity and the corresponding lump sum. In the deferred case participants choose between a fair annuity starting at retirement age and a lump sum also received when entering retirement. In both cases subjects are asked in a consecutive question to choose an annuitization rate between $0 \%$ and $100 \%$ in steps of $10 \%$. The probability of choosing an annuity over a lump sum increases in both cases by almost $20 \%$ from the oldest to the youngest $10 \%$ of the sample, whereas the annuitization rate 
increases by about $12 \%$. Hyperbolic discounting, compared to exponential time discounting, should lead to an undervaluation of payments in the near future and an overvaluation of later payments. In the annuity context, this means for young people, because of their high survival probabilities, that only relatively few (expected) payments are undervalued and most payments are overvalued resulting in an overvaluation of the annuity. The opposite is true for older individuals. By splitting the sample into a group of subjects who answered simple time preference questions inconsistently and a group that gave time consistent answers it is shown that this effect indeed is driven by the time preferences of participants. The finding is robust to the inclusion of various control variables. Additional important factors are subjective life expectancy, financial literacy and risk aversion. Expecting a long life results in high annuitization rates. Also, participants who are more financially literate and more risk averse prefer annuities over lump sums and choose higher annuitization rates. These findings not only help to better understand the annuity puzzle but might also be used to increase real life annuitization rates. In the deferred case the switch of preferences over time can be seen as a self-control problem. Therefore, introducing a commitment device allowing people to bind or precommit their behavior could help to increase real life annuitization. 


\section{References}

Abdellaoui, M., A. E. Attema, and H. Bleichrodt. 2010. Intertemporal tradeoffs for gains and losses: An experimental measurement of discounted utility. The Economic Journal 120 (545): 845-866.

Agnew, J. R., L. R. Anderson, J. R. Gerlach, and L. R. Szykman. 2008. Who chooses annuities? an experimental investigation of the role of gender, framing, and defaults. The American Economic Review 98 (2): 418 422.

Ahlbrecht, M. and M. Weber. 1997. An empirical study on intertemporal decision making under risk. Management Science 43 (6): 813-826.

Ainslie, G. 1975. Specious reward: A behavioral theory of impulsiveness and impulse control. Psychological Bulletin 82 (4): 463-496.

Ainslie, G. and R. Herrnstein. 1981. Preference reversal and delayed reinforcement. Animal Learning \& Behavior 9 (4): 476-482.

Ameriks, J., A. Caplin, S. Laufer, and S. van Nieuwerburgh. 2011. The joy of giving or assisted living? using strategic surveys to separate public care aversion from bequest motives. Journal of Finance 66 (2): 519-561.

Andreoni, J. and C. Sprenger. 2012. Estimating time preferences from convex budgets. American Economic Review 102 (7): 3333-3356.

Baucells, M. and F. H. Heukamp. 2012. Probability and time trade-off. Management Science 58 (4): 831-842.

Benartzi, S., A. Previtero, and R. H. Thaler. 2011. Annuitization puzzles. Journal of Economic Perspectives 25 (4): 143-164.

Benzion, U., A. Rapoport, and J. Yagil. 1989. Discount rates inferred from decisions: An experimental study. Management Science 35 (3): 270-284.
Beshears, J., J. J. Choi, D. Laibson, B. C. Madrian, and J. Sakong. 2011. Self control and liquidity: How to design a commitment contract. Working Paper .

Beshears, J., J. J. Choi, D. Laibson, B. C. Madrian, and S. P. Zeldes. 2012. What makes annuitization more appealing? National Bureau of Economic Research Working Paper Series No. 18575.

Bickel, W. K., A. L. Odum, and G. J. Madden. 1999. Impulsivity and cigarette smoking: delay discounting in current, never, and ex-smokers. Psychopharmacology 146 (4): 447-454.

Brown, J. R. 2001. Private pensions, mortality risk, and the decision to annuitize. Journal of Public Economics 82 (1): 29-62.

Brown, J. R. 2007. Rational and behavioral perspectives on the role of annuities in retirement planning. National Bureau of Economic Research Working Paper Series No. 13537.

Brown, J. R. and J. M. Poterba. 2000. Joint life annuities and annuity demand by married couples. The Journal of Risk and Insurance 67 (4): 527-553.

Brown, J. R., J. R. Kling, S. Mullainathan, and M. V. Wrobel. 2008. Why don't people insure late-life consumption? a framing explanation of the under-annuitization puzzle. The American Economic Review 98 (2): 304309.

Brown, J. R., A. Kapteyn, E. F. Luttmer, and O. Mitchell. 2012. Do consumers know how to value annuities? complexity as a barrier to annuitization. RAND Working Paper.

Brunner, J. and S. Pech. 2006. Adverse selection in the annuity market with sequential and simultaneous insurance demand. The GENEVA Risk and Insurance Review 31 (2): 111-146. 
Buetler, M. and F. Teppa. 2007. The choice between an annuity and a lump sum: Results from swiss pension funds. Journal of Public Economics 91 (10): 1944 1966.

Chalmers, J. and J. Reuter. 2012. How do retirees value life annuities? evidence from public employees. Review of Financial Studies 25 (8): 2601-2634.

Davidoff, T., J. R. Brown, and P. A. Diamond. 2005. Annuities and individual welfare. The American Economic Review 95 (5): 1573-1590.

DellaVigna, S. 2009. Psychology and economics: Evidence from the field. Journal of Economic Literature 47 (2): 315-372.

DellaVigna, S. and U. Malmendier. 2006. Paying not to go to the gym. The American Economic Review 96 (3): 694-719.

Drichoutis, A. and R. Nayga. 2013. A reconciliation of time preference elicitation methods. Working Paper.

Dushi, I. and A. Webb. 2004. Household annuitization decisions: simulations and empirical analyses. Journal of Pension Economics and Finance 3 (02): 109-143.

Epper, T. and H. Fehr-Duda. 2013. Balancing on a budget line: Comment on Andreoni and Sprenger's "risk preferences are not time preferences". Working Paper.

Finkelstein, A. and J. Poterba. 2004. Adverse selection in insurance markets: Policyholder evidence from the U.K. annuity market. Journal of Political Economy 112 (1): 183-208.

Frederick, S., G. Loewenstein, and T. O’Donoghue. 2002. Time discounting and time preference: A critical review. Journal of Economic Literature 40 (2): 351-401.

Friedman, B. M. and M. J. Warshawsky. 1990. The cost of annuities: Implications for saving behavior and be- quests. The Quarterly Journal of Economics 105 (1): 135-154.

Hamermesh, D. S. 1985. Expectations, life expectancy, and economic behavior. The Quarterly Journal of Economics 100 (2): 389-408.

Hardisty, D. J., K. F. Thompson, D. H. Krantz, and E. U. Weber. 2013. How to measure time preferences: An experimental comparison of three methods. Judgment and Decision Making 8 (3): 236-249.

Harrison, G. W., M. I. Lau, and M. B. Williams. 2002. Estimating individual discount rates in Denmark: A field experiment. The American Economic Review 92 (5): 1606-1617.

Harvey, C. M. 1986. Value functions for infinite-period planning. Management Science 32 (9): 1123-1139.

Horneff, W. J., R. H. Maurer, O. S. Mitchell, and M. Z. Stamos. 2009. Asset allocation and location over the life cycle with investment-linked survival-contingent payouts. Journal of Banking \& Finance 33 (9): 16881699.

Hu, W.-Y. and J. S. Scott. 2007. Behavioral obstacles in the annuity market. Financial Analysts Journal 63 (6): 71-82.

Hurd, M. D. 1989. Mortality risk and bequests. Econometrica 57 (4): 779-813.

Ifcher, J. and H. Zarghamee. 2011. Happiness and time preference: The effect of positive affect in a randomassignment experiment. American Economic Review 101 (7): 3109-3129.

Irwin, J. R. and G. H. McClelland. 2001. Misleading heuristics and moderated multiple regression models. Journal of Marketing Research 38 (1): 100-109. 
Johnson, R., L. Burman, and D. Kobes. 2004. Annuitized Wealth at Older Ages: Evidence from the Health and Retirement Study. Urban Institute.

Kirby, K. N. and N. N. Marakovic. 1995. Modeling myopic decisions: Evidence for hyperbolic delaydiscounting within subjects and amounts. Organizational Behavior and Human Decision Processes 64 (1): 22-30.

Koopmans, T. C. 1960. Stationary ordinal utility and impatience. Econometrica 28 (2): 287-309.

Kotlikoff, L. J. and A. Spivak. 1981. The family as an incomplete annuities market. Journal of Political Economy 89 (2): 372-391.

Laibson, D. 1997. Golden eggs and hyperbolic discounting. The Quarterly Journal of Economics 112 (2): 443 477.

Laibson, D., A. Repetto, and J. Tobacman, 2003. "a debt puzzle.". In Aghion, P., R. Frydma, J. Stiglitz, and M. Woodford (Editors), Knowledge, Information, and Expectations in Modern Macroeconomics: In Honor of Edmund S. Phelps, Princeton University Press.

Loewenstein, G. and D. Prelec. 1992. Anomalies in intertemporal choice: Evidence and an interpretation. The Quarterly Journal of Economics 107 (2): 573-597.

Lusardi, A. and O. S. Mitchell. 2007. Baby boomer retirement security: The roles of planning, financial literacy, and housing wealth. Journal of Monetary Economics 54 (1): 205-224.

Meier, S. and C. Sprenger. 2010. Present-biased preferences and credit card borrowing. American Economic Journal: Applied Economics 2 (1): 193-210.

Meier, S. and C. Sprenger. 2012. Discounting financial literacy: Time preferences and participation infinancial education programs. Journal of Economic Behavior \& Organization Forthcoming.
Mirowsky, J. 1999. Subjective life expectancy in the us: correspondence to actuarial estimates by age, sex and race. Social Science \& Medicine 49 (7): 967-979.

Mitchell, O. S. and J. F. Moore. 1998. Can americans afford to retire? new evidence on retirement saving adequacy. The Journal of Risk and Insurance 65 (3): $371-400$.

Mitchell, O. S., J. M. Poterba, M. J. Warshawsky, and J. R. Brown. 1999. New evidence on the money's worth of individual annuities. The American Economic Review 89 (5): 1299-1318.

Mueller, S. and M. Weber. 2011. How good are mutual fund ratings and can they be improved? - empirical evidence for finanztest. European Financial Management Forthcoming.

Murthi, M., J. M. Orszag, and P. R. Orszag. 2000. The value for money of annuities in the U.K.: Theory, experience and policy. Journal of Pensions Management May 2000 (1).

Noor, J. 2009. Hyperbolic discounting and the standard model: Eliciting discount functions. Journal of Economic Theory 144 (5): 2077 - 2083.

Norton, E. C., H. Wang, and C. Ai. 2004. Computing interaction effects and standard errors in logit and probit models. Stata Journal 4 (2): 154-167.

Nosic, A. and M. Weber. 2010. How risky do i invest: The role of risk attitudes, risk perceptions, and overconfidence. Decision Analysis 7 (3): 282-301.

Pang, G. and M. Warshawsky. 2010. Optimizing the equity-bond-annuity portfolio in retirement: The impact of uncertain health expenses. Insurance: Mathematics and Economics 46 (1): 198-209.

Phelps, E. S. and R. A. Pollak. 1968. On second-best national saving and game-equilibrium growth. Review of Economic Studies 35 (2): 185-199. 
Previtero, A. 2012. Stock market returns and annutization at older ages. AFA 2013 San Diego Meetings Paper.

Purcal, S. and J. Piggott. 2008. Explaining low annuity demand: An optimal portfolio application to Japan. Journal of Risk and Insurance 75 (2): 493-516.

Read, D. 2005. Monetary incentives, what are they good for? Journal of Economic Methodology 12 (2): 265 276.

Sayman, S. and A. Öncüler. 2009. An investigation of time inconsistency. Management Science 55 (3): 470 482.

Shu, S. B., R. Zeithammer, and J. Payne. 2013. Consumer preferences for annuities: Beyond NPV. Working Paper.

Sorger, G. 2007. Time-preference and commitment. Journal of Economic Behavior \& Organization 62 (4): 556578.

Spiller, S. A., G. J. Fitzsimons, J. G. Lynch, and G. H. J. McClelland. 2013. Spotlights, floodlights, and the magic number zero: Simple effects tests in moder- ated regression. Journal of Marketing Research 50 (2): 277-288.

Strotz, R. H. 1955. Myopia and inconsistency in dynamic utility maximization. The Review of Economic Studies 23 (3): 165-180.

Sutter, M., M. G. Kocher, D. Glätzle-Rüetzler, and S. T. Trautmann. 2013. Impatience and uncertainty: Experimental decisions predict adolescents' field behavior. American Economic Review 103 (1): 510-531.

Thaler, R. 1981. Some empirical evidence on dynamic inconsistency. Economics Letters 8 (3): 201-207.

Thaler, R. H. and H. M. Shefrin. 1981. An economic theory of self-control. Journal of Political Economy 89 (2): 392-406.

van Rooij, M., A. Lusardi, and R. Alessie. 2011. Financial literacy and stock market participation. Journal of Financial Economics 101 (2): 449-472.

Yaari, M. E. 1965. Uncertain lifetime, life insurance, and the theory of the consumer. The Review of Economic Studies 32 (2): 137-150. 


\section{Appendix}

\section{A Derivations with respect to $r$}

\section{A.1 Derivation of $\mathbf{D}(\mathbf{x})$ with respect to $r$}

\section{Immediate case}

In the immediate case $\mathrm{D}(\mathrm{x})$ is defined as $E P V_{H B}(x)-A$ :

$$
E P V_{H B}(x)-A=A \frac{\sum_{t=0}^{120-x} p(x+t \mid x)(1+t)^{-r}}{\sum_{t=0}^{120-x} p(x+t \mid x)(1+i)^{-t}}-A .
$$

The first derivative of $\mathrm{D}(\mathrm{x})$ with the respect to $\mathrm{r}$ is:

$$
\frac{\delta\left[E P V_{H B}(x)-A\right]}{\delta r}=\frac{\delta\left[E P V_{H B}(x)\right]}{\delta r}=-A \frac{\sum_{t=0}^{120-x} p(x+t \mid x)(1+t)^{-r} \ln (1+t)}{\sum_{t=0}^{120-x} p(x+t \mid x)(1+i)^{-t}}<0 .
$$

The probability $p(x+t \mid x)$, the hyperbolic discount factor $(1+t)^{-r}$, the exponential discount factor $(1+i)^{-t}$ and the term $\ln (1+t)$ are always positive. Therefore the whole fraction is positive and multiplied by $-A$ which results in a negative first derivative of $\mathrm{D}(\mathrm{x})$ with respect to $\mathrm{r}$.

\section{Deferred case}

In the deferred case $\mathrm{D}(\mathrm{x})$ is defined as $E P V_{H B_{\text {annuity }}}(x)-E P V_{H B_{\text {lumpsum }}}(x)$ :

$$
D(x)=A \frac{\sum_{t=0}^{(120-66)} p(66+t \mid 66)(1+(t+66-x))^{-r}}{\sum_{t=0}^{(120-66)} p(66+t \mid 66)(1+i)^{-t}}-\frac{A}{(1+(66-x))^{r}}
$$

The first derivative of $\mathrm{D}(\mathrm{x})$ with the respect to $\mathrm{r}$ is:

$$
\begin{gathered}
\frac{\delta\left[E P V_{H B_{\text {annuity }}}(x)-E P V_{H B_{\text {lumpsum }}}(x)\right]}{\delta r} \\
\Leftrightarrow-A \frac{\sum_{t=0}^{(120-66)} p(66+t \mid 66)(1+(t+66-x))^{-r} \ln (1+(t+66-x))}{\sum_{t=0}^{(120-66)} p(66+t \mid 66)(1+i)^{-t}}+A \frac{\ln (1+(66-x))}{(1+(66-x))^{r}} \\
\Leftrightarrow-A\left[\frac{\ln (1+(66-x))}{(1+(66-x))^{r}}\right]\left[\frac{\sum_{t=1}^{(120-66)} p(66+t \mid 66)(1+(t+66-x))^{-r} \ln (1+(t+66-x))}{\sum_{t=0}^{(120-66)} p(66+t \mid 66)(1+i)^{-t}}-1\right]
\end{gathered}
$$

The part outside the square bracket is always negative for $x<66 .{ }^{17}$ The part inside the square bracket is always positive if :

$$
\sum_{t=1}^{(120-66)} p(66+t \mid 66)(1+(t+66-x))^{-r} \ln (1+(t+66-x))>\sum_{t=0}^{(120-66)} p(66+t \mid 66)(1+i)^{-t}
$$

\footnotetext{
${ }^{17}$ For $x=66$ the derivative of $\mathrm{D}(\mathrm{x})$ would be zero as the immediate case would then be considered.
} 
Assuming $i=0$ gives an upper bound for the right side of the inequality. Using the latest German life tables leads to:

$$
\sum_{t=1}^{(120-66)} p(66+t \mid 66)(1+(t+66-x))^{-r} \ln (1+(t+66-x))>16.11 .
$$

This inequality is only fulfilled for all $\mathrm{x}$ as long as $r<0.3479$. Therefore the sign of the first derivative of $\mathrm{D}(\mathrm{x})$ with respect to $\mathrm{r}$ strongly depends on the parameter $\mathrm{r}$.

\section{A.2 Derivation of $\Delta \mathbf{D}(\mathbf{x})$ with respect to $r$}

Immediate case

$\Delta D(x)$ is defined as $D(x+1)-D(x)=E P V_{H B}(x+1)-A-\left(E P V_{H B}(x)-A\right)$ which can be written as $E P V_{H B}(x+1)-E P V_{H B}(x)$. Therefore the first derivative of $\Delta D(x)$ with respect to $\mathrm{r}$ is:

$$
\frac{\delta \Delta D(x)}{\delta r}=\frac{\delta D(x+1)-D(x)}{\delta r}=\frac{\delta D(x+1))}{\delta r}-\frac{\delta D(x))}{\delta r}
$$

using equation (12) this leads to:

$$
\frac{\delta \Delta D(x)}{\delta r}=-A \frac{\sum_{t=0}^{119-x} p(x+1+t \mid x+1)(1+t)^{-r} \ln (1+t)}{\sum_{t=0}^{119-x} p(x+1+t \mid x+1)(1+i)^{-t}}+A \frac{\sum_{t=0}^{120-x} p(x+t \mid x)(1+t)^{-r} \ln (1+t)}{\sum_{t=0}^{120-x} p(x+t \mid x)(1+i)^{-t}} .
$$

The difference between the two fractions depends on the difference of the survival probability of an $\mathrm{x}+1$ year old decision maker and the survival probability of an $\mathrm{x}$ year old one $(p(x+1+t \mid x+1)$ vs. $p(x+t \mid x))$. Using the latest German life tables results in:

$$
A \frac{\sum_{t=0}^{119-x} p(x+1+t \mid x+1)(1+t)^{-r} \ln (1+t)}{\sum_{t=0}^{119-x} p(x+1+t \mid x+1)(1+i)^{-t}}<A \frac{\sum_{t=0}^{120-x} p(x+t \mid x)(1+t)^{-r} \ln (1+t)}{\sum_{t=0}^{120-x} p(x+t \mid x)(1+i)^{-t}},
$$

$\forall x \in[0 ; 120]$ and $i, r \in(0 ; \infty)$. Therefore the first derivative of $\Delta D(x)$ is positive.

\section{Deferred case}

For the deferred case the sign of the first derivative of $\Delta D(x)$ depends on the parameter $\mathrm{r}$. This can be seen by writing $\frac{\delta \Delta D(x)}{\delta r}$ as:

$$
\frac{\delta \Delta D(x)}{\delta r}=\frac{\delta D(x+1)-D(x)}{\delta r}=\frac{\delta D(x+1))}{\delta r}-\frac{\delta D(x))}{\delta r}
$$

From equation (16) it follows that the sign of $\frac{\delta(x+1))}{\delta r}$ and $\frac{\delta D(x))}{\delta r}$ depends on the parameter are and therefore also the sign of the whole derivative depends on it. 


\section{Discount functions}

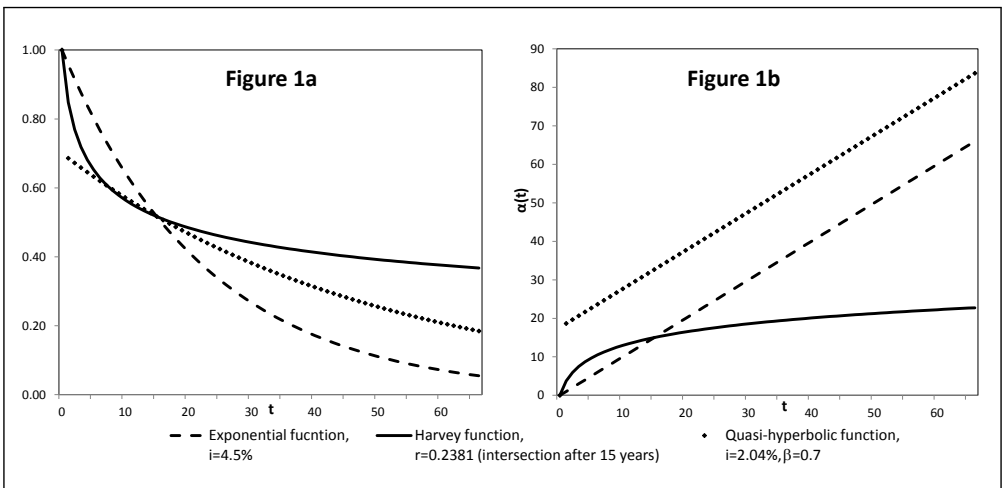

Figure 1: Figure 1a reports the exponential discount function $D F_{E X P}(t)=(1+i)^{-t}$ with $i=4.5 \%$, the Harvey function $D F_{H B}(t)=$ $(1+t)^{-r}$ with $r=0.2381$ and the quasi-hyperbolic discount function with $i=2.04 \%$ and $\beta=0.7$. Figure $1 \mathrm{~b}$ reports the function $\alpha(t)$ for the three discount functions.

\section{Difference of EPV immediate annuity and lump sum}

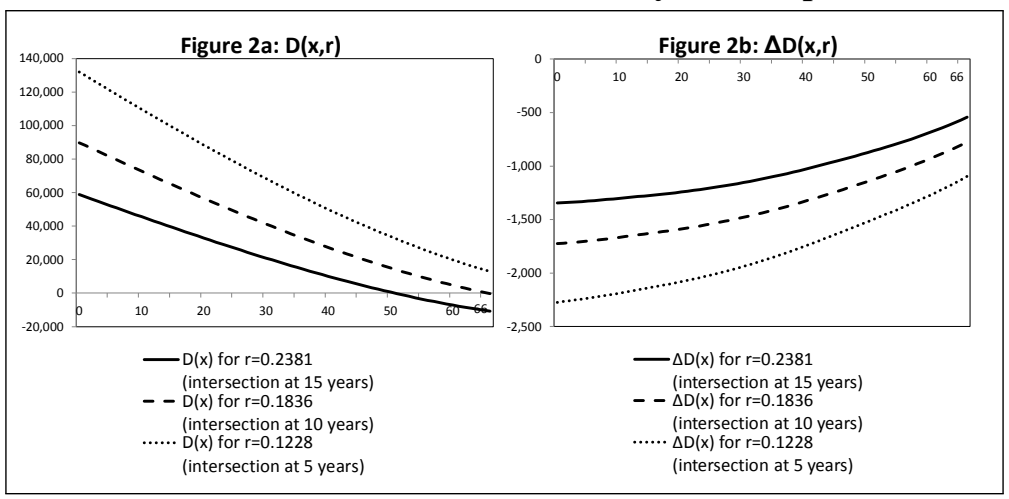

Figure 2: This figure reports the difference $D(x)$ of the expected present value of a fair immediate annuity and a lump sum payment of $A=100,000 E U R$ for a hyperbolic decision maker (figure 2a). The change in $D(x)$ is defined as $\Delta(x)=$ $D(x+1)-D(x)$ and reported in figure $2 \mathrm{~b}$. "Intersection" indicates for which period the weight of the hyperbolic function equals the weight of an exponential discount function with $i=4.5 \%$.

\section{Critical age dependent on hyperbolic discounting parameter $\mathbf{r}$}

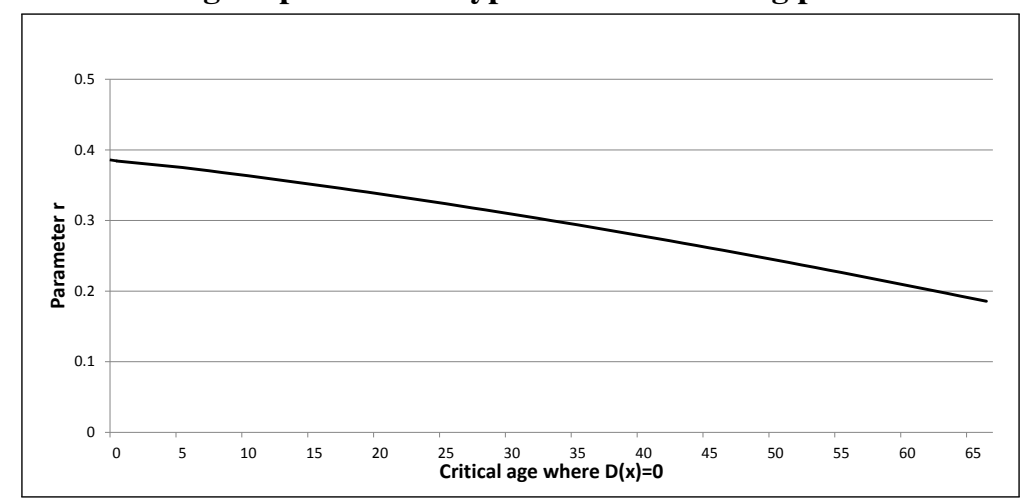

Figure 3: This figure reports the critical age for which $D(x)=0$ dependent on the parameter $r$ of the hyperbolic discount function $D F_{H B}=(1+t)^{-r}$. 
Difference of EPV deferred annuity and lump sum

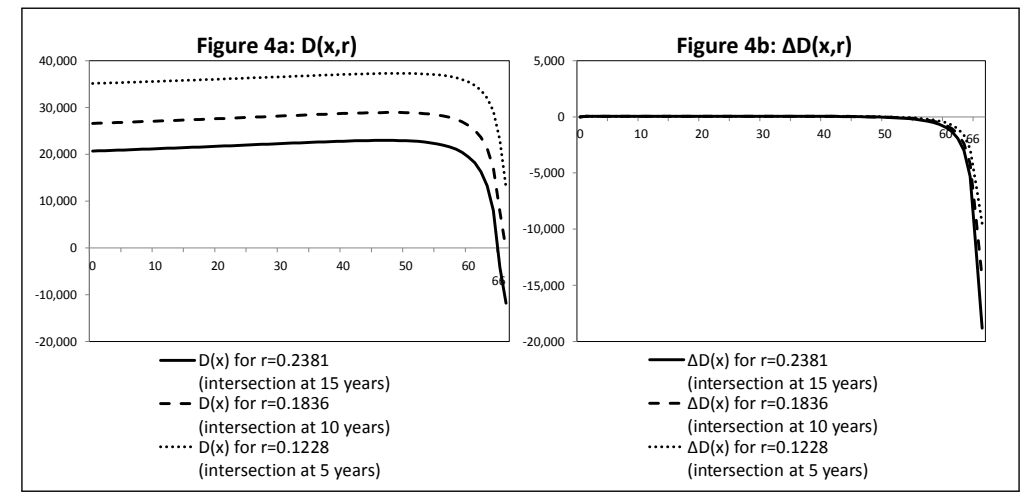

Figure 4: This figure reports the difference $D(x)$ of the expected present value of a fair deferred annuity and a deferred lump sum payment of $A=100,000 E U R$ for a hyperbolic decision maker (figure 4a). The change in $D(x)$ is defined as $\Delta(x)=D(x+1)-D(x)$ and reported in figure $4 \mathrm{~b}$. "Intersection" indicates for which period the weight of the hyperbolic function equals the weight of an exponential discount function with $i=4.5 \%$.

\section{Fraction of participants for each possible annuitization rate}

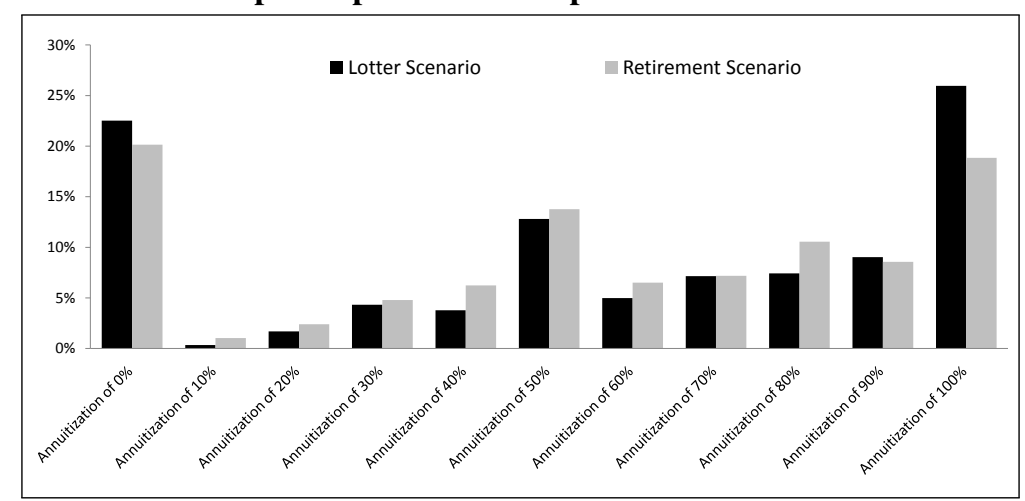

Figure 5: This figure reports the fraction of participants for each possible annuitization rate

Variance of annuitization rate by age

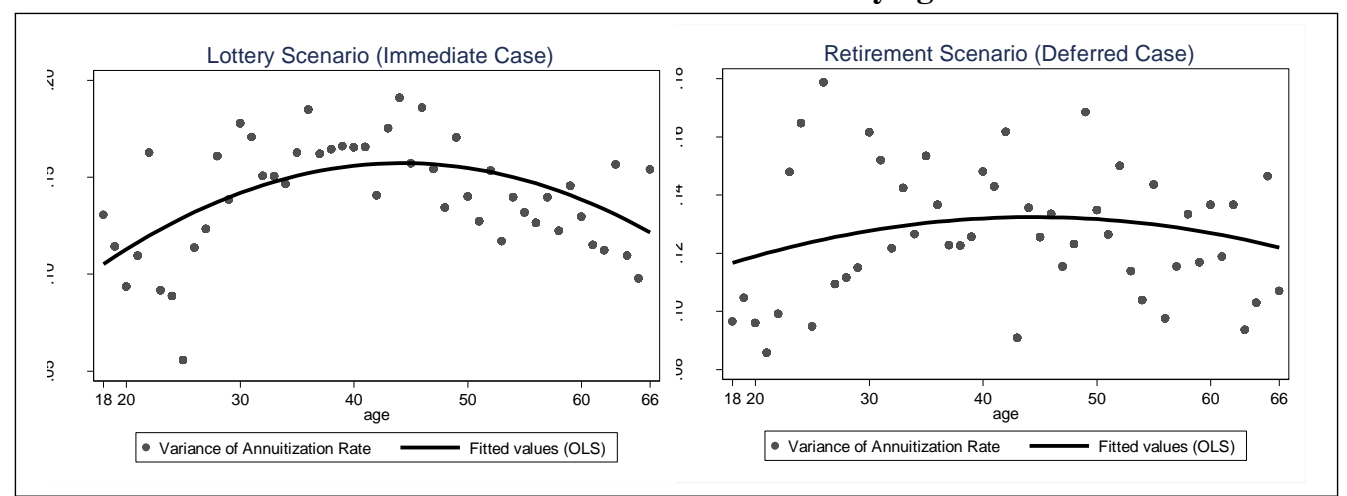

Figure 6: This figure reports the variance of the annuitization rate by age (18-66) for the lottery and retirement scenario. Solid line represents fitted values from an OLS regression with age and age squared as explanatory variables. 


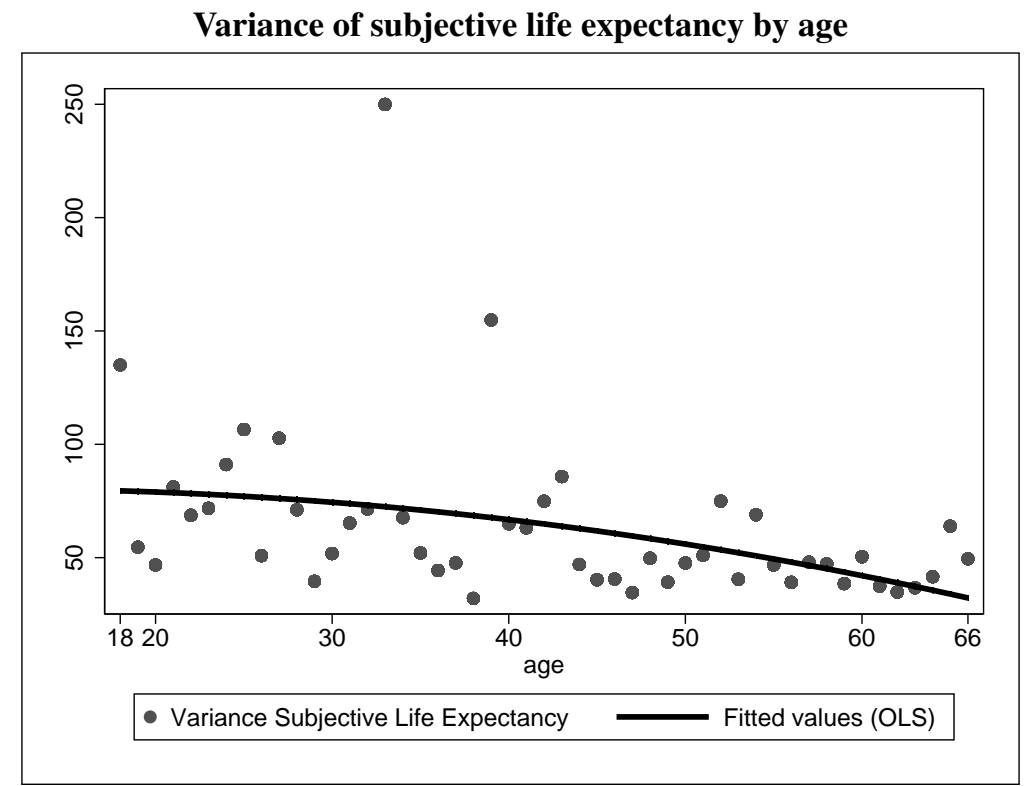

Figure 7: This figure reports the variance of subjective life expectancy by age (18-66). Solid line represent fitted values from an OLS regression on the variance of the subjective life expectancy with age and age squared as explanatory variables

Table 1: Possible choices between a lump sum of $A$ and the corresponding fair annuity. We assumed a constant interest rate of $4.5 \%$ and used latest life tables for Germany. The objective life expectancy for a 66 year old male (female) was 82.74 (85.84).

\begin{tabular}{rcc}
\hline Amount (A) in EUR & $\begin{array}{c}\text { Fair monthly annuity } \\
\text { male at age 66 }\end{array}$ & $\begin{array}{c}\text { Fair monthly annuity } \\
\text { female at age 66 }\end{array}$ \\
\hline 100,000 & 763.76 & 649.08 \\
300,000 & $2,291.28$ & $1,947.24$ \\
500,000 & $3,818.80$ & $3,245.40$ \\
700,000 & $5,346.32$ & $4,543.56$ \\
$1,000,000$ & $7,637.60$ & $6,490.80$ \\
\hline
\end{tabular}


Table 2: Online survey summary statistics for participants with age below 67. Number of observations vary between 2672 (income) and 2944.

\begin{tabular}{|c|c|c|c|}
\hline Variable & Mean & (Median) & Std. Dev. \\
\hline \multicolumn{4}{|l|}{ Annuity Choice } \\
\hline Annuity $0 / 1$ & 0.57 & & 0.50 \\
\hline Annuitization Rate & 0.56 & & 0.37 \\
\hline \multicolumn{4}{|l|}{ Demographics } \\
\hline Age & 41.77 & $(43.00)$ & 13.16 \\
\hline Gender & 0.83 & & 0.37 \\
\hline Income & $3,443.41$ & $(3,000.00)$ & $3,162.56$ \\
\hline Number of Children & 0.84 & & 1.19 \\
\hline High School Degree & 0.91 & & 0.28 \\
\hline University Degree & 0.66 & & 0.47 \\
\hline Married & 0.51 & & 0.50 \\
\hline \multicolumn{4}{|l|}{ Time Preferences } \\
\hline Time Inconsistent $\mathrm{i}=3 \%$ & 0.20 & & 0.40 \\
\hline Time Inconsistent $\mathrm{i}=11 \%$ & 0.25 & & 0.44 \\
\hline Time Inconsistent $\mathrm{i}=31 \%$ & 0.18 & & 0.39 \\
\hline Always inconsistent & 0.07 & & 0.26 \\
\hline Impatience (1-7) & 3.91 & & 1.64 \\
\hline \multicolumn{4}{|l|}{ Controls } \\
\hline Risk Aversion (1-7) & 3.90 & & 1.47 \\
\hline Loss Aversion (1-7) & 4.30 & & 1.60 \\
\hline Financial Literacy Score van Rooij (0-4) & 3.49 & & 0.73 \\
\hline Financial Literacy Score Extra (0-2) & 0.59 & & 0.73 \\
\hline Life Expectancy (Males) & 83.29 & & 8.02 \\
\hline Life Expectancy (Females) & 83.87 & & 7.43 \\
\hline Planed Retirement Age & 64.70 & & 4.53 \\
\hline Owns Private Pension Insurance & 0.63 & & 0.48 \\
\hline Certainty of Social Security (1-7) & 3.05 & & 1.82 \\
\hline
\end{tabular}

Table 3: Results of logistic regression. Dependent variable is annuity0/1, an indicator variable that equals 1 if participants choose the annuity and 0 if they choose the lump sum. $* * *, * *$ and $*$ indicate significance on the 1\%,5\% and 10\%-level. Sample consisting only of participants aged between 61 and 66. Age(c) is the mean-centered age variable for this subsample.

\begin{tabular}{llc}
\hline Variable & Coeff. & Std. Error \\
\hline Age $(\mathrm{c})$ & $-0.245^{* *}$ & 0.116 \\
Scenario & -0.366 & 0.258 \\
Interaction Age(c)-Scenario & 0.029 & 0.037 \\
\hline \hline $\mathrm{N}=254$ & & \\
\hline
\end{tabular}


Table 4: Results of logistic regression. Dependent variable is annuity $0 / 1$, an indicator variable that equals 1 if participants choose the annuity and 0 for the lump sum. The sample is split by scenario (lottery vs. retirement). $* * *, * *$ and * indicate significance on the $1 \%, 5 \%$ and $10 \%$-level.

\begin{tabular}{|c|c|c|c|c|}
\hline \multirow[b]{2}{*}{ Variable } & \multicolumn{2}{|c|}{$\begin{array}{l}\text { Lottery Scenario } \\
\text { (immediate case) }\end{array}$} & \multicolumn{2}{|c|}{$\begin{array}{c}\text { Retirement Scenario } \\
\text { (deferred case) }\end{array}$} \\
\hline & Coeff. & Odds Ratio & Coeff. & Odds Ratio \\
\hline \multicolumn{5}{|l|}{$\overline{\text { Demographics }}$} \\
\hline Age & $-0.028 * * *$ & 0.972 & $-0.019 * * *$ & 0.981 \\
\hline Gender & 0.017 & 1.017 & -0.217 & 0.805 \\
\hline Income $(\log )$ & 0.118 & 1.124 & 0.086 & 1.089 \\
\hline Number of Children & -0.318 & 0.967 & -0.069 & 0.933 \\
\hline High School Degree & -0.429 & 0.651 & 0.183 & 1.200 \\
\hline University Degree & 0.128 & 1.137 & 0.199 & 1.221 \\
\hline Married & -0.103 & 0.902 & -0.147 & 0.863 \\
\hline \multicolumn{5}{|l|}{ Time Preferences } \\
\hline Always Inconsistent & $-0.670 * *$ & 0.512 & -0.197 & 0.821 \\
\hline Always Consistent & $-0.318 * *$ & 0.727 & -0.007 & 0.993 \\
\hline Impatience (1-7) & 0.051 & 1.052 & -0.030 & 0.970 \\
\hline \multicolumn{5}{|l|}{ Controls } \\
\hline Risk aversion (1-7) & $0.135 * *$ & 1.145 & 0.071 & 1.074 \\
\hline Loss aversion (1-7) & -0.036 & 0.965 & -0.044 & 0.957 \\
\hline Financial Literacy Score 1-5 (0-5) & $0.152 *$ & 1.164 & 0.099 & 1.104 \\
\hline Financial Literacy Question 6 & $-0.246 *$ & 0.782 & -0.067 & 0.935 \\
\hline Life Expectancy & $0.044 * * *$ & 1.045 & $0.059 * * *$ & 1.061 \\
\hline Planed Retirement Age & 0.001 & 1.001 & -0.001 & 0.999 \\
\hline Owns Private Pension Insurance & 0.162 & 1.176 & $0.554 * * *$ & 1.739 \\
\hline Certainty of Social Security & 0.053 & 1.055 & 0.058 & 1.059 \\
\hline \multicolumn{5}{|l|}{ Magnitude Controls } \\
\hline Magnitude2 (lump sum $=250 \mathrm{k}$ ) & 0.188 & 1.207 & -0.215 & 0.807 \\
\hline Magnitude3 (lump sum $=500 \mathrm{k}$ ) & -0.280 & 0.756 & -0.038 & 0.962 \\
\hline Magnitude4 (lump sum = 750k) & -0.208 & 0.813 & $-0.457 * *$ & 0.633 \\
\hline Magnitude5 (lump sum = 1,000k) & 0.002 & 1.002 & $-0.527 * *$ & 0.590 \\
\hline Magnitude Relatively Low & -0.427 & 0.652 & -0.492 & 0.612 \\
\hline Time Sum & 0.000 & 1.000 & -0.492 & 0.612 \\
\hline Number of Obs & 1,101 & & 1088 & \\
\hline Correctly Classified & $63.36 \%$ & & $63.36 \%$ & \\
\hline Area under ROC Curve & 0.6626 & & 0.6896 & \\
\hline
\end{tabular}


Table 5: Results of logistic regression for a subsample of participants of age below 51. The subsample is split by scenario (lottery vs. retirement). Dependent variable is annuity $0 / 1$, an indicator variable that equals 1 if participants choose the annuity and 0 for the lump sum. $* * * * *$ and $*$ indicate significance on the $1 \%, 5 \%$ and $10 \%$-level.

\begin{tabular}{|c|c|c|c|c|}
\hline \multirow[b]{2}{*}{ Variable } & \multicolumn{2}{|c|}{$\begin{array}{c}\text { Lottery Scenario } \\
\text { (immediate case) }\end{array}$} & \multicolumn{2}{|c|}{$\begin{array}{l}\text { Retirement Scenario } \\
\text { (deferred case) }\end{array}$} \\
\hline & Coeff. & Odds Ratio & Coeff. & $\overline{\text { Odds Ratio }}$ \\
\hline \multicolumn{5}{|l|}{$\overline{\text { Demographics }}$} \\
\hline Age & $-0.038 * * *$ & 0.962 & -0.014 & 0.986 \\
\hline Risk aversion & $0.134 *$ & 1.144 & 0.062 & 1.064 \\
\hline Loss aversion & -0.049 & 0.952 & 0.029 & 1.030 \\
\hline Financial Literacy Score 1-5 (0-5) & $0.200 * *$ & 1.222 & $0.203 * *$ & 1.226 \\
\hline Financial Literacy Question 6 & -0.218 & 0.804 & -0.055 & 0.946 \\
\hline Life expectancy & $0.037 * * *$ & 1.038 & $0.051 * * *$ & 1.052 \\
\hline Time Preferences & Yes & & Yes & \\
\hline Other Controls & Yes & & Yes & \\
\hline Magnitude Controls & Yes & & Yes & \\
\hline Number of Obs & 824 & & 824 & \\
\hline Correctly classified & $62.58 \%$ & & $61.99 \%$ & \\
\hline Area under ROC Curve & 0.6517 & & 0.6928 & \\
\hline
\end{tabular}

Table 6: Results of logistic regression for a subsample of time inconsistent and consistent participants. Dependent variable is annuity $0 / 1$, an indicator variable that equals 1 if participants choose the annuity and 0 for the lump sum. $* * *, * *$ and $*$ indicate significance on the $1 \%, 5 \%$ and $10 \%$-level.

\begin{tabular}{|c|c|c|c|c|}
\hline \multirow[b]{2}{*}{ Variable } & \multicolumn{2}{|c|}{ Time inconsistent } & \multicolumn{2}{|c|}{ Time consistent } \\
\hline & Coeff. & Odds Ratio & Coeff. & Odds Ratio \\
\hline \multicolumn{5}{|l|}{$\overline{\text { Demographics }}$} \\
\hline Age & $-0.031 * * *$ & 0.969 & $-0.017 * * *$ & 0.983 \\
\hline Risk Aversion & 0.120 & 1.128 & 0.085 & 1.089 \\
\hline Loss Aversion & -0.088 & 0.916 & -0.020 & 0.980 \\
\hline Financial Literacy Score 1-5 (0-5) & $0.349 * * *$ & 1.418 & 0.057 & 1.058 \\
\hline Financial Literacy Question 6 & -0.344 & 0.709 & -0.139 & 0.870 \\
\hline Life Expectancy & $0.076 * * *$ & 1.079 & $0.049 * * *$ & 1.050 \\
\hline Time Preferences & No & & No & \\
\hline Other Controls & Yes & & Yes & \\
\hline Scenario Controls & Yes & & Yes & \\
\hline$\overline{\text { Number of Obs }}$ & 389 & & 1829 & \\
\hline Correctly Classified & $60.34 \%$ & & $64.17 \%$ & \\
\hline Area under ROC Curve & 0.7035 & & 0.6566 & \\
\hline
\end{tabular}


Table 7: Results of logistic regression for three subsamples of participants in the lottery scenario with different time preferences (measured by parameter $r$ ). Dependent variable is annuity0/1, an indicator variable that equals 1 if participants choose the annuity and 0 for the lump sum. $* * *, * *$ and $*$ indicate significance on the $1 \%, 5 \%$ and $10 \%$-level.

\begin{tabular}{|c|c|c|c|c|}
\hline & \multirow[t]{2}{*}{ Full Subsample } & \multicolumn{3}{|c|}{ Subsample split by parameter $r$} \\
\hline & & $\mathrm{r}=\mathrm{small}$ & $\mathrm{r}=$ medium & $\mathrm{r}=$ large \\
\hline Variable & Coeff. & Coeff. & Coeff. & Coeff. \\
\hline Age & $-0.033 * * *$ & $-0.060 * * *$ & $-0.034 * *$ & -0.029 \\
\hline Risk aversion & 0.029 & 0.067 & -0.007 & 0.062 \\
\hline Financial Literacy & 0.047 & -0.154 & -0.020 & 0.226 \\
\hline Financial Literacy Question 6 & $-0.735 * *$ & $-0.961 *$ & -0.587 & -1.008 \\
\hline Life Expectancy & $0.049 * * *$ & $0.075^{*}$ & $0.073 * *$ & 0.015 \\
\hline Parameter $r$ medium & -0.294 & - & - & - \\
\hline Parameter $r$ large & $-0.636^{*}$ & - & - & 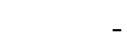 \\
\hline Time Preferences & No & No & No & No \\
\hline Other Controls & \multirow{2}{*}{\multicolumn{4}{|c|}{$\begin{array}{l}\text { only if significant in previous regressions } \\
\text { only if significant in previous regressions }\end{array}$}} \\
\hline Magnitude Controls & & & & \\
\hline Number of Obs & 291 & 95 & 125 & $\overline{71}$ \\
\hline Correctly classified & $59.75 \%$ & $60.58 \%$ & $62.04 \%$ & $57.67 \%$ \\
\hline Area under ROC Curve & 0.6923 & 0.7630 & 0.6887 & 0.6667 \\
\hline
\end{tabular}


Table 8: Results of OLS regressions with annuitization rate as dependent variable. Annuitization rate can take values from $0 \%$ to $100 \%$ in steps of $10 \%$. The sample is split by scenario (lottery vs. retirement). ${ }^{* * *}, * *$ and $*$ indicate significance on the $1 \%, 5 \%$ and $10 \%$-level.

\begin{tabular}{|c|c|c|c|c|}
\hline \multicolumn{3}{|c|}{$\begin{array}{l}\text { Lottery Scenario } \\
\text { (immediate case) }\end{array}$} & \multicolumn{2}{|c|}{$\begin{array}{c}\text { Retirement Scenario } \\
\quad(\text { deferred case })\end{array}$} \\
\hline Variable & Coeff. & Std. Error & Coeff. & Std. Error \\
\hline \multicolumn{5}{|l|}{$\overline{\text { Demographics }}$} \\
\hline Age & $-0.004 * * *$ & 0.001 & -0.002 & 0.001 \\
\hline Gender & 0.030 & 0.034 & -0.019 & 0.031 \\
\hline Income (log) & 0.013 & 0.016 & $0.028 * *$ & 0.014 \\
\hline Number of Children & 0.001 & 0.012 & -0.010 & 0.012 \\
\hline High School Degree & -0.034 & 0.045 & $0.081 *$ & 0.047 \\
\hline University Degree & 0.025 & 0.029 & 0.009 & 0.027 \\
\hline Married & -0.041 & 0.031 & -0.007 & 0.031 \\
\hline \multicolumn{5}{|l|}{ Time Preferences } \\
\hline Always Inconsistent & $-0.110 * *$ & 0.049 & -0.011 & 0.047 \\
\hline Always Consistent & -0.022 & 0.024 & -0.001 & 0.023 \\
\hline Impatience (1-7) & $0.016 * *$ & 0.007 & -0.006 & 0.007 \\
\hline \multicolumn{5}{|l|}{$\overline{\text { Controls }}$} \\
\hline Risk aversion (1-7) & $0.025 * *$ & 0.010 & $0.023 * *$ & 0.009 \\
\hline Loss aversion (1-7) & -0.002 & 0.009 & -0.005 & 0.008 \\
\hline Financial Literacy Score 1-5 (0-5) & $0.026^{*}$ & 0.013 & 0.006 & 0.014 \\
\hline Financial Literacy Question 6 & $-0.055 * *$ & 0.025 & -0.002 & 0.026 \\
\hline Life Expectancy & $0.007 * * *$ & 0.002 & $0.007 * * *$ & 0.002 \\
\hline Planed Retirement Age & $0.000 * * *$ & $\quad 0.000$ & $0.000 * * *$ & 0.000 \\
\hline Owns Private Pension Insurance & $0.062 * *$ & 0.024 & $0.098 * * *$ & 0.023 \\
\hline Certainty of Social Security & 0.005 & 0.006 & $0.019 * * *$ & 0.006 \\
\hline \multicolumn{5}{|l|}{ Magnitude Controls } \\
\hline Magnitude2 (lump sum = 250k) & 0.012 & 0.039 & -0.019 & 0.039 \\
\hline Magnitude $3($ lump sum $=500 \mathrm{k})$ & $-0.076^{*}$ & 0.042 & -0.007 & 0.040 \\
\hline Magnitude4 (lump sum $=750 \mathrm{k})$ & $-0.073^{*}$ & 0.041 & -0.047 & 0.039 \\
\hline Magnitude5 (lump sum $=1,000 \mathrm{k})$ & -0.064 & 0.041 & $-0.114 * * *$ & 0.038 \\
\hline Magnitude Relatively Low & -0.087 & 0.065 & -0.087 & 0.060 \\
\hline Time Sum & 0.000 & 0.000 & -0.000 & 0.0600 \\
\hline$\overline{\overline{\text { Number of Obs }}}$ & 1,101 & & 1088 & \\
\hline$R^{2}$ & 0.0755 & & 0.0907 & \\
\hline
\end{tabular}

